\title{
The Status of Planning for Risk Management in Private Schools in Karak Governorate from the Perspective of Teachers
}

\author{
Khaled A. Al-Sarairah \\ Deanship of Scientific Research \\ Mutah University - Jordan \\ dr.khaledsarairah@gmail.com
}

\author{
Samar Salem Shlooh \\ Educational Administration \\ Mutah University - Jordan \\ samarsalemshlooh@gmail.com
}

Received 9/1/2020

Accepted 16/2/2020

\begin{abstract}
:
This study aims at finding out the status of planning for risk management in private schools in Karak governorate from the perspective of teachers. To achieve the objectives of the study, a descriptive-survey methodology is used. The tool of the study is developed and its validity and reliability are verified. It is distributed to a random sample of (272) female and male teachers in private schools in Karak governorate. The study concludes with several results, the most important of which are: the status of planning for risk management in private schools in Karak governorate from teachers' point of view is of medium level. The field of decision-making, and addressing risk, capacity is of the highest level. The last level is the awareness of the nature of risk in school, which is of a medium level. The results also show that there are no statistical significant differences in the means of the total score of the status of planning for risk management in private schools in Karak governorate from teachers' point of view attributed to school level and experience.
\end{abstract}

Keywords: Planning, Risk Management, Private Schools, Karak Governorate, Jordan. 


\section{واقع التخطيط لإدارة المخاطر في المدارس الخاصة التابعة لمديريات التربية والتعليم بمحافظة الكرك من وجهة نظر المعلمين}

$$
\begin{aligned}
& \text { سمر سالم الثلوح } \\
& \text { إدارة تربوية - كلية العلوم التربوية } \\
& \text { جامعة مؤتة - الأردن }
\end{aligned}
$$

samarsalemshlooh@gmail.com

قبول البحث $2020 / 2$ / 2

\author{
خالد أحمد الصرايرة \\ عمادة البحث العلمي \\ جامعة مؤتنة - الأردن
}

dr.khaledsarairah@gmail.com

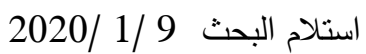

(الملخص:

هدفت الدراسة الحالية إلى معرفة واقع التخطيط لإدارة المخاطر في المدارس الخاصة التابعة لمديريات التربية والتعليم بمحافظة الكرك من

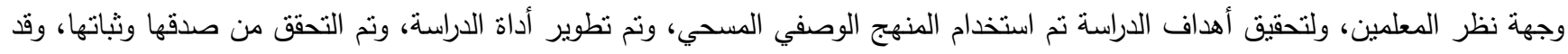

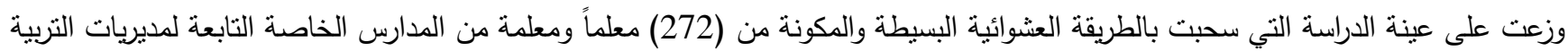
والتعليم بمحافظة الكرك. وقد توصلت الدراسة إلى نتائج أهمها أن واقع التخطيط لإدارة المخاطر في الددارس الخاصة التابعة لمديريات التربية والتعليم بمحافظة الكرك من وجهة نظر المعلمين جاء بدرجة متوسطة، وقد جاء مجال القدرة على اتخاذ القرار ومواجهة المخاطر بالمرتبة الأولى

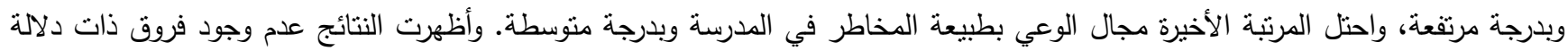

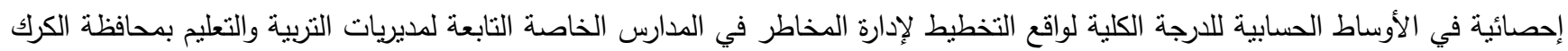
من وجهة نظر المعلمين تُعزى لمستوى المدرسة، والخبرة. الكلمات المفتاحية: التخطيط، إدارة المخاطر ، الددارس الخاصة، محافظة الكرك، الأردن.

المقدمة:

تُعدّ الإدارة المدرسية الجهة المسؤولة عن إعداد الخطط

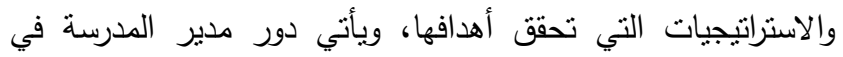
إنتاج الطريق الأفضل لمسيرة عملية التعلم والتعليم في مدرسته لإحداث النطوير المطلوب في مختلف جوانب العملية التربوية والارتقاء بمخرجاتها التعليمية. وتزداد أهمية دور مدير المدرسة نتيجة

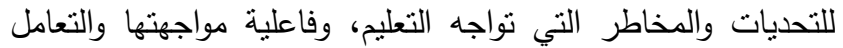
معها بما ينسجم مع متطلبات العصر وتوجهات الدولة لتحسين العطلية التعليمبة وتجويدها (8). ويُعدّ التخطيط عملية شاملة مستمرة، تتضمن التهديدات والمخاطر، وكيفية إدارتها والتعامل معها، والسعي لإيجاد البدائل المناسبة، وهي تقوم على الربط بين منطلبات إدارة المخاطر في

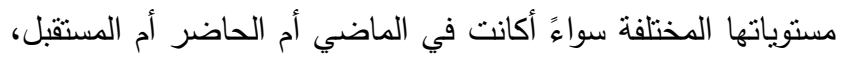

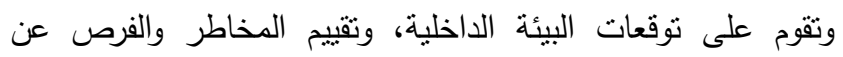

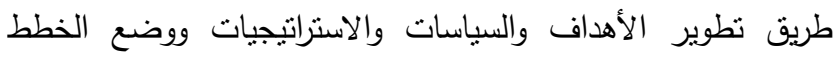

التعليم هو اللبنة الأساسية لنطور المجتمعات ورقيها وتقدمها، فالتعلم هو تصميم منظم ومقصود للخبرة التي تعمل على مساعدة

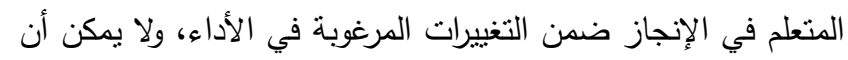

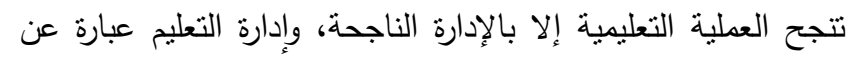
عملية هدروسة تسند إلى إدارات النعليم لتحقيق الأهداف والنتائج

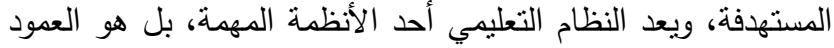
الفقري لبقية الأنظمة، لأهينها في حياة المجتمعات وسر نهضنتها

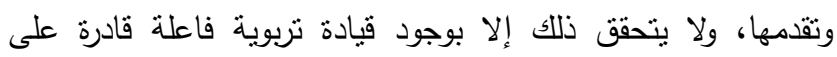
التخطيط السليم وتتخيص الداء ومكامن الخلل، وتجاوز كل المعوقات والتحديات، وبما أننا نواكب الثورة التعليمية، التي يشهدها العالم وما يوافقها من تغيرات منسارعة، فقد صار لزاما على المؤسسات التزبوية مجاراة التغيرات الجديدة ومواجهة متطلبات العصر الحديث من خلال تطوير القيادات التزبوية فيها وتتميتها، ورفع كفاءتها وزيادة فاعليتها، لتتمكن من الوصول إلى بر الأمان بهذه المؤسسات. 
لتعقدها وتشابكها، وذلك على الرغم من أن المخاطر أصبحت جزءءاً

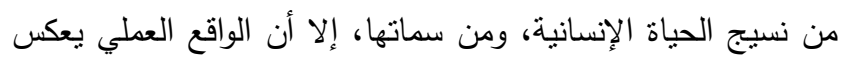

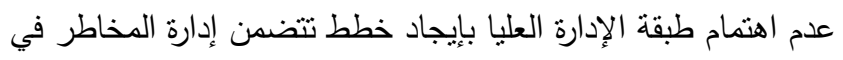

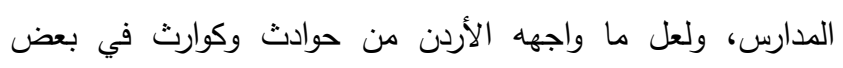

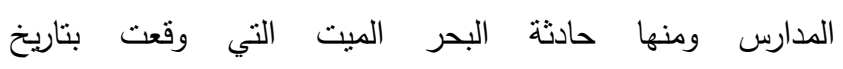
2018/10/25، والتي راح ضحيتها 21 شخصاً، ونتائج الحريق الذي لئي حدث في مدرسة مصعب بن عمير الثانوية للبنين بلواء الرمثا بتاريخ 2019/12/8، والذي أدى إلى إصابة 27 شخصا يؤكد مشكلة لئل الدراسة، ويحتم دراسة واقع المخاطر وإدارتها في المدارس للمحافظة إلمابة على بيئة مدرسية آمنة تتسم بأقل مخاطر مدكنة، وتتضدمن خططها

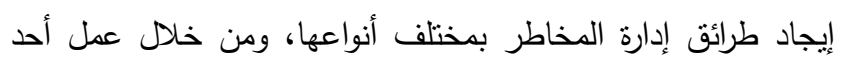

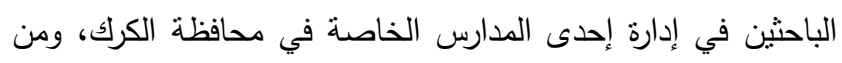

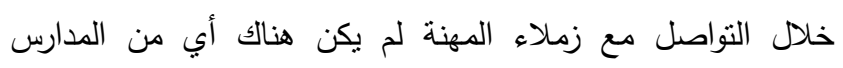

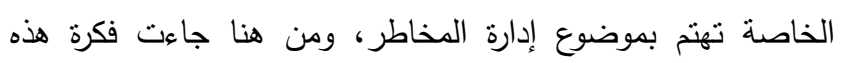

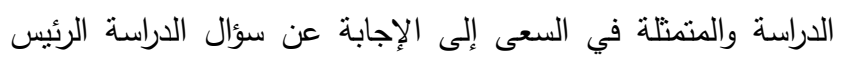

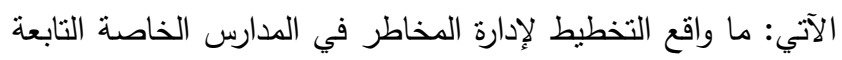

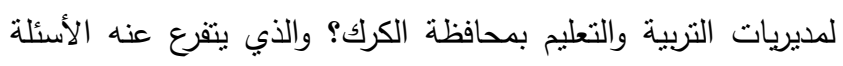
الآتية:

1. ما واقع التخطيط لإدارة المخاطر في الددارس الخاصة

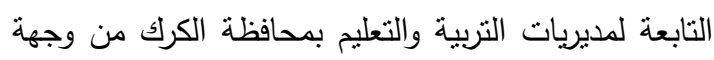
نظر المعلمين؟ 2. هل نتوجد فروق ذات دلالة إحصائية عند مستوى دلالة

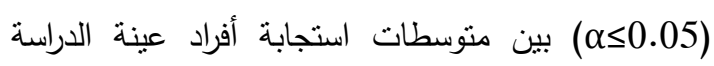
على واقع التخطيط لإدارة المخاطر في المدارس الخاصة

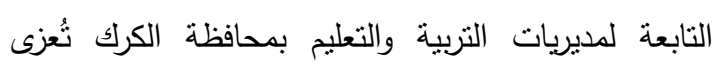

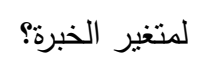
3. هل نوجد فروق ذات دلالة إحصائية عند مسنوى دلالة

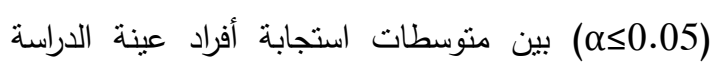

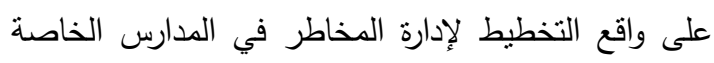

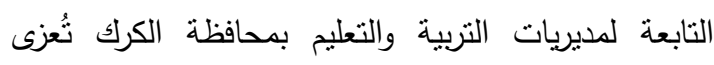

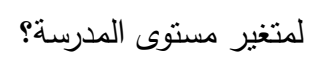

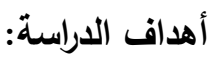

سعت هذه الدراسة إلى تحقيق الأهداف المبينة نالياً:

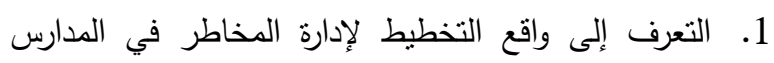

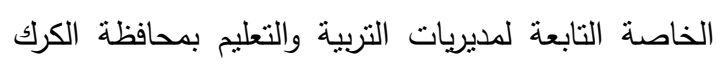
من وجهة نظر المعلمين. 2. التعرف إلى الفروق بين متوسطات استجابة أفراد عينة

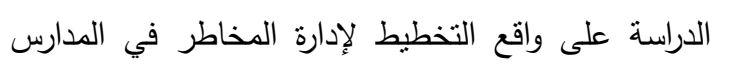

التتفيذية، ومثابعة تتفيذها باستمرار، ويتوجب على إدارات مؤسسات

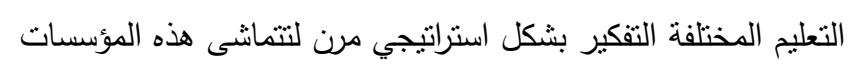
مع التهديدات والمخاطر التي قد نطرأ من خلال المتغيرات البيئية

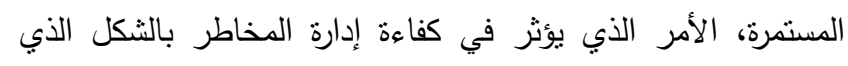

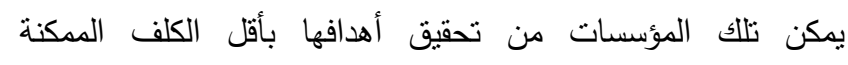

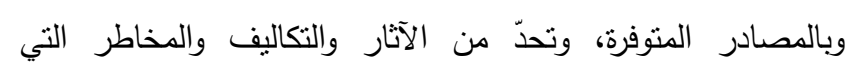
تواجهها(18).

وتعد إدارة المخاطر ذات أهمية كبيرة لما تشكله من توجه

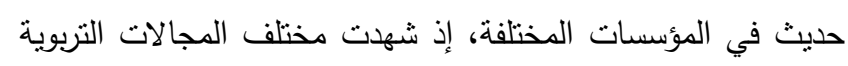

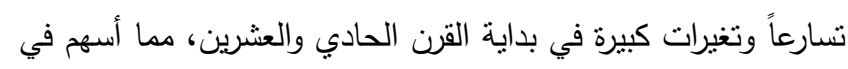

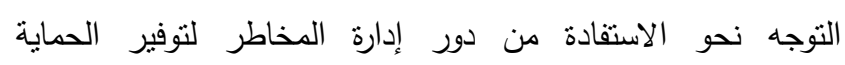

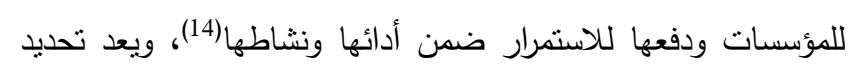

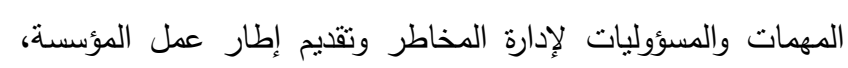

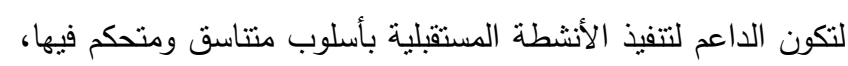

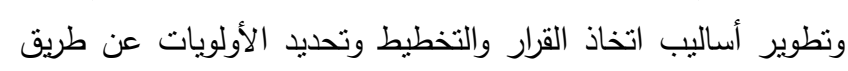

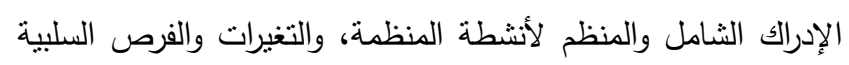

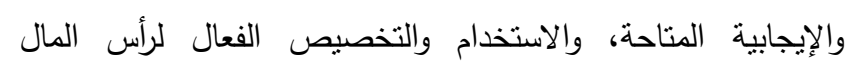
والموارد المتاحة (20).

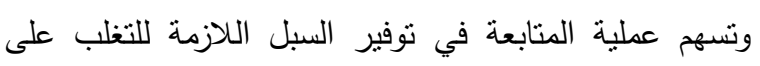
النقص في البيانات والمعلومات، وذللك لضمان الجودة في أداء المدرسة طبقاً للمعايير، فمن خلال عملية تتظيم الأفكار لمواجهة

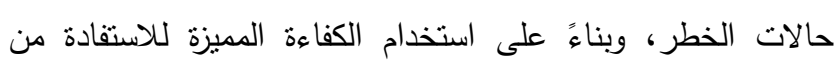

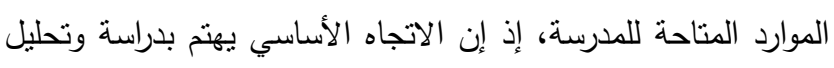

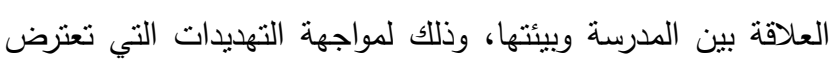

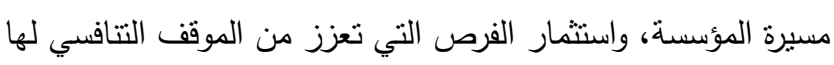

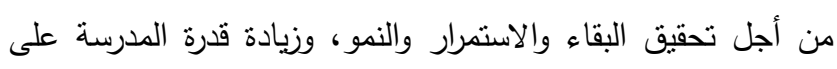
إدارة علاقتها بالبيئة التي تعمل فيها (12).

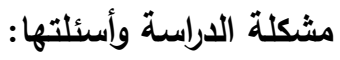

تعمل بيئة العمل الداخلية في الددارس على إثغالئل مدال مدير

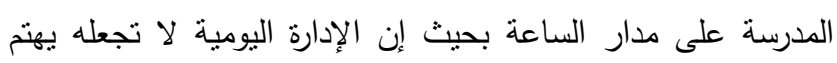

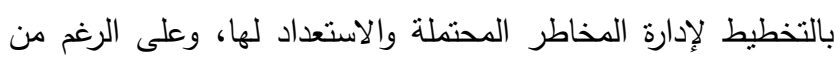

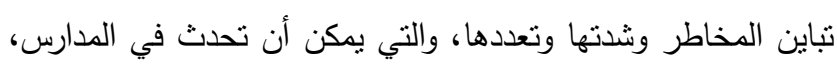

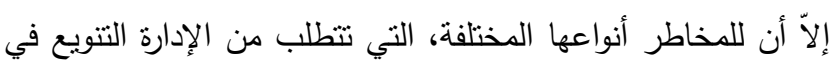

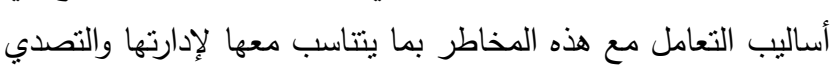

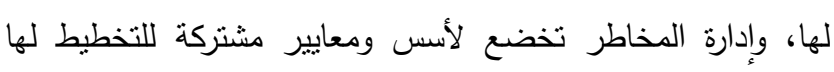
والإعداد الفعال لتجنب وقوعها، أو التخفيف من حدتها ومن الآثار التي تنترتب على وقوعها. إن الأساليب المبنية على أسس اجتهادية وغير علمية ليست

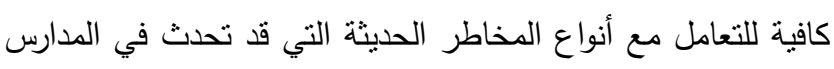




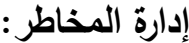

يعد ليندمان (Lindman) أول من درس المخاطر ، إذ درس أثز الحريق الهائل في منطقة بوسطن Boston، وفحص تأثير الموت

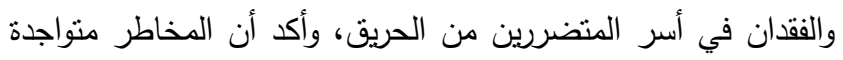

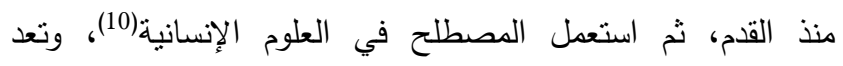
المخاطر جزءا مهما من حياة كل مؤسسة تربوية أو غيرها، دون

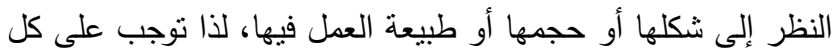

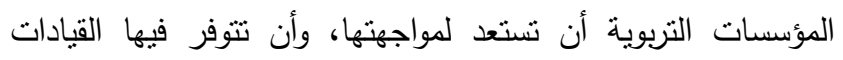

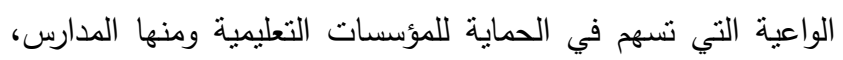

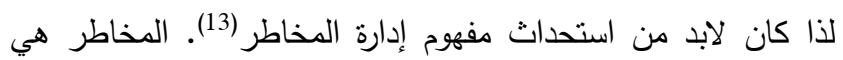
حالة من عدم التأكد والقلق الذي يلازم متخذ القرار نتيجة عدم تأكده من نتيجة قراراته التي قد بنتج عنها خسائر مادية معنوية(1). أما إدارة

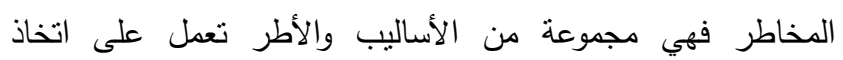
القرارات السريعة والعقلانية لمواجهة تحديات وتطورات معينة، بهدف

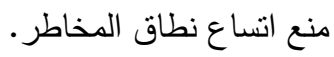
فلإدارة المخاطر دور فعال وبالغ الأهمية في بقاء المؤسسات التربوية واستمرارها ومن ضمنها الددارس، فهي ضرورية لبناء الأجيال وإعدادهم للمستقبل ضمن بيئة مطمئنة وآمنة(7)، فالإدارة الددرسية تسعى دائما لتحقيق الأهداف المنشودة، للعمل على تتمية الطلبة من كافة النواحي، والسعي المستمر لتحسين العملية التعلمية والتعليمية

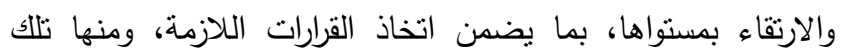
القرارات المتعلقة بالمخاطر (3). وتعرف عملية إدارة المخاطر بأنها إدارة

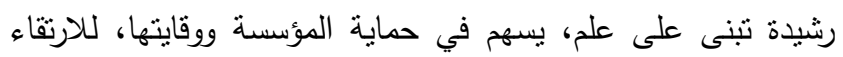
بأدائها، والإسهام أيضا بحل المشكلات التي قد تحدث في المستقبل ومعالجتها(29). وعرفها بليزك وبرجسوت (Pliszka \& Borgsdorf) على أنها مجموعة الإجراءات والأنشطة الخاصة بالتخطيط والرقابة والتظيم والقيادة لموارد المؤسسة من أجل تقليل الآثار المحتملة للمخاطر التي قد تتعرض لها نلك الموارد(5).

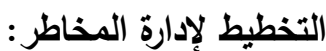

وهي عملية تقييم وقياس المخاطر التي قد تشكل تهديداً للمؤسسة باستخدام الأدوات الكمية والنوعية عن طريق الكية الربط بين

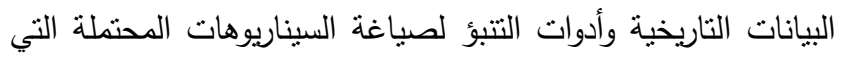
قد تشكل تهديداً للمؤسسة، ويعد تقييم وقياس المخاطر ذا أهمية كبيرة للمؤسسات وكذللك لجمهور المتعاملين معها والمُلالك الذين سيقودون عملية صنع القرار في تحديد أنواع وحجم الاستثمار والأهداف قصيرة

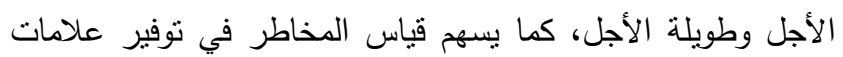

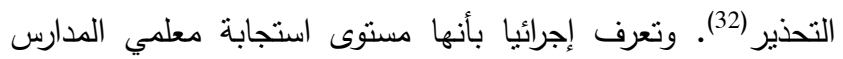
على أداة قياس مستوى واقع التخطيط لإدارة المخاطر في المدارس لئنس
الخاصة التابعة لمديريات التربية والتعليم بمحافظة الكرك من وجهة نظر المعلمين تُعزى لمتغير الخبرة.

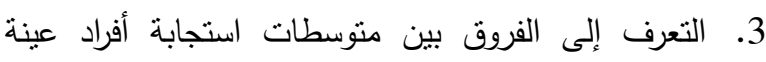

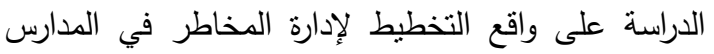
الخاصة التابعة لمديريات التربية والتعليم بدحافظة الكرك من وجهة نظر المعلمين تُعزى لمتغير مستوى المدرسة. أهمية الدراسة:

تكمن أهمية هذه الدراسة في سعيها للكثف عن واقع التخطيط لإدارة المخاطر في المدارس الخاصة التابعة لمديريات التربية والتعليم بمحافظة الكرك من وجهة نظر المعلمين من وجهة نظر المعلمين، وتظهر أهمية الدراسة من خلال: الأهمية العلمية: تُعدّ هذه الدراسة من الدراسات الحديثة والقليلة

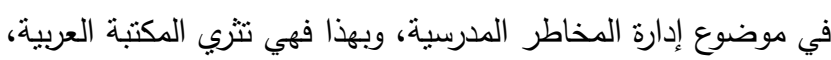
وتفتح آفاقا جديدة للباحثني لتتاول هذا الموضوع من جوانب مختلفة، وذلك بهدف الوصول إلى دراسات يمكن أن تسهم في دعم الأدب

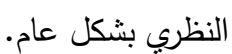

الأهية العملية: قد تقيد هذه الدراسة التعرف إلى أهمية

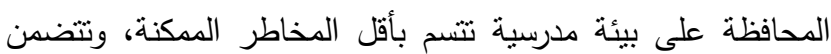
خططها إيجاد طرائق إدارة المخاطر بمختلف أنواعها، فمن شأن

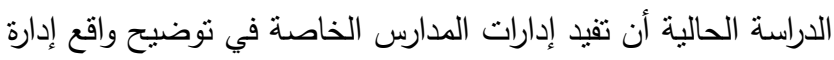

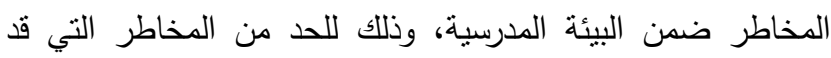
تتعرض لها بعض الددارس الخاصة في محافظة الكرك، وقد تقيد مديري المدارس ومتخذي القرار في وزارة التربية والتعليم والباحثين

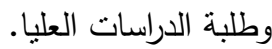

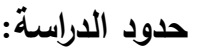

$$
\text { الحد البشري: معلمو الدراسة على الحدود الآتية: }
$$

الحد المكاني: الددارس الخاصة التابعة لمديريات التربية والتعليم

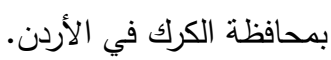
الحد الزماني: الفصل الدراسي الثاني من العام المدرسي 2018

الحد الموضوعي: واقع التخطيط لإدارة المخاطر في المدارس الخاصة التابعة لمديريات التربية والتعليم بمحافظة الكرك من وجهة الآدرة

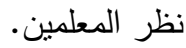

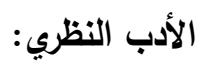

تتاول الأدب النظري مفهوم إدارة الدخاطر، والتعرف إلى إدارة المخاطر في المدارس وأهميتها. 
تتسم الأوامر والتعليمات اللازمة لإدارة الخطر بالوضوح والثفافية

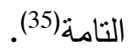

وقد أنثار ايليوت(26) إلى أن وجود فريق لإدارة المخاطر في

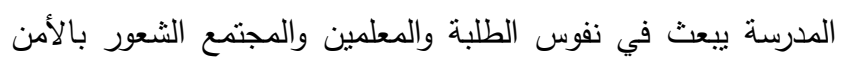

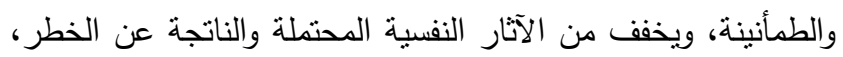
كما بساعد على وضع خطة إستراتيجية تهدف إلى الوقاية من الخطر

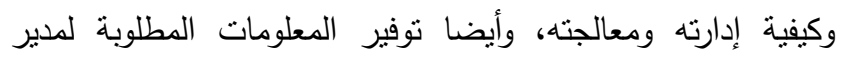
المدرسة حتى تكون بيئة متكاملة بتطورات الأحداث.

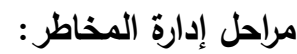

تمر إدارة المخاطر في مراحل متعددة، نتاولها العديد من الدمان الباحثين ومن أهمها ما ذكره(4) والتي لخصها في فيما يأتي:

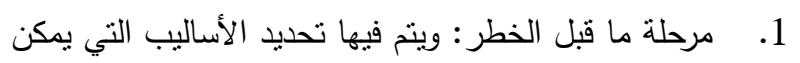

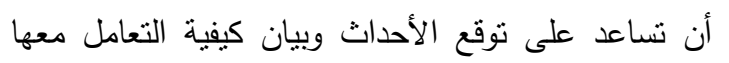

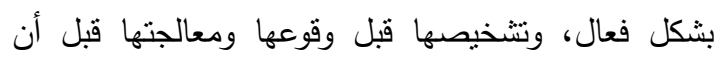
تشتند خطورتها، وهي من أهم المراحل. مرحلة أثناء الخطر : وهي مرحلة اتخاذ القرار المناسب في التراحل أثناء وقوع الخطر ، إذ يجب النظر لجميع النواحي لمعالجة

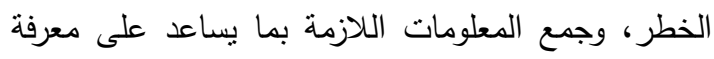
الأسباب وضمان حلها. مرحلة ما بعد الخطر: وفي هذه المرحلة يتم مساعدة العاملين للعودة للأوضاع الطبيعية بالإضافة لعمل نقييم

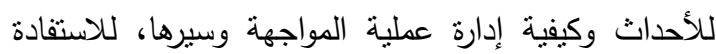
منها في المرات القادمة، وتتشمل هذه المرحلة عقد الدمات اجتماعات دورية تتضمن أخصائيين نفسيين واجتماعيين، والقيام بإعداد بيان رسمي للرد على الاستفسارات وتحديد الأشخاص المتأثزين بالخطر من الطلبة والعاملين.

\section{أنواع المخاطر في المدارس:}

تتعدد المخاطر التي تتعرض لها الددارس ومنها الإدارية والبيئية

والتكنولوجية، وتتلخص بما يأتي (19):

1. المخاطر الإنشائية والهندسية: وتتعلق بعدم ملاعمة البيئة

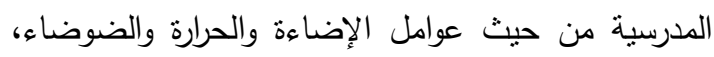

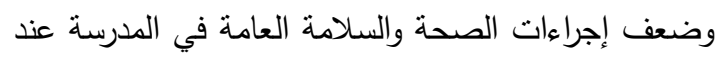

إنثاء المبنى الددرسي وتجهيزه بلوحات كهربائية

ونوصيلات مناسبة وتشغيل أجهزة الحاسوب وأدوات

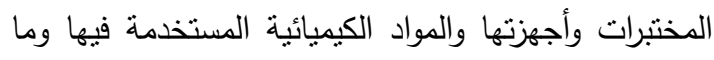

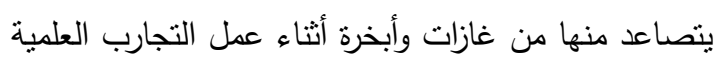
والورش الصناعية، وغياب الأمان والصحة المهنية، والتي

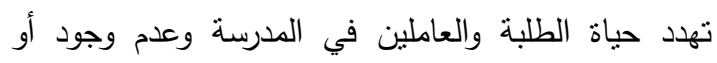
تعطل أجهزة الإنذار ومكافحة الحرائق، وغياب إجراءات
الخاصة التابعة لمديريات التربية والتعليم بمحافظة الكرك التي طورها

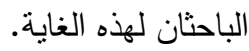
ويرى الباحثان أن دراسة إدارة المخاطر تنطلب معرفة لطبيعتها

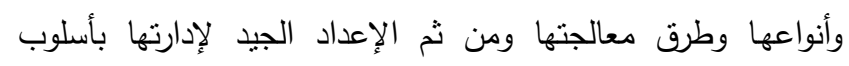
علمي مبني على قواعد وبيانات صحيحة وبناء قدرات وطنية مؤهلة

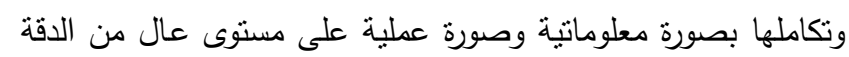
والوضوح والإثقان.

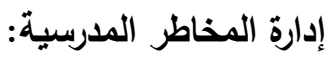

تُعرّف إدارة المخاطر في الددارس بأنها الاستخدام الفعال

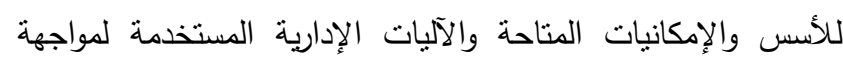
الخطر المنوقع حدوثه في المدرسة، والتي يمكن تحقيقها لخدمة العملية التعليمية(11). وهي أيضاً مهارة نوعية يتطلب تكوينها وتطويرها التدريب والنطبيق المستمر لمديري الددارس، من خلال القدرة على ونى

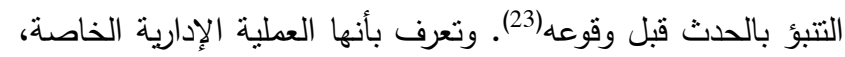

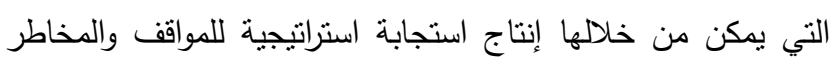
من خلال مجموعة من العاملين والمديرين ليستخدموا مهاراتهم للتقليل من الخسائر التي قد تتنج إلى الحد الأدنى (2).

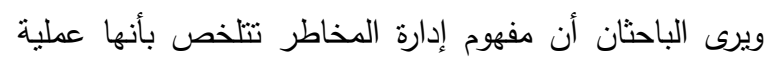
تتسم بالديناميكية المنظمة والمستمرة، والتي قد يشترك في تطبيقان الديقها

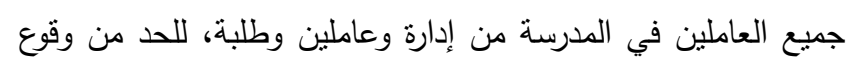

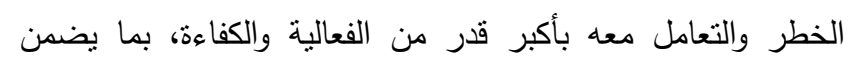
تحقيق الأهداف المنشودة. أما مفهوم التخطيط لإدارة المخاطر فعرفه الباحثان بأنه

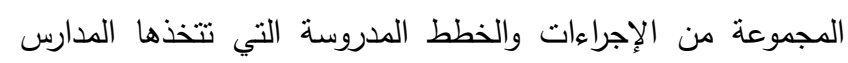
لمواجهة الأخطار المتوقعة في المستقبل، بهدف الحد من حدوثها.

\section{أهمية إدارة المخاطر المدرسية:}

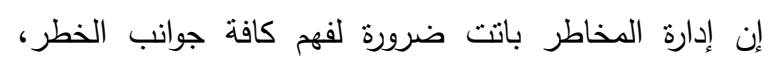
فالخطر حدث مفاجئ، يحدث بوقت ضيق ويصعب التتبؤ به، يسهر

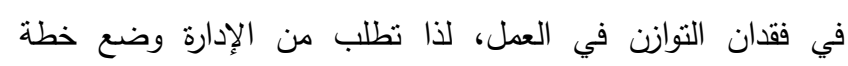

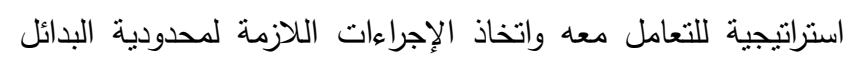
والحلول عند وقوعه.

وتبرز أهمية إدارة المخاطر في المدرسة من خلا سعيها

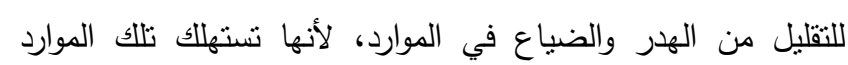

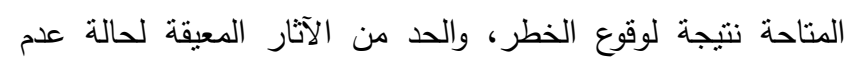

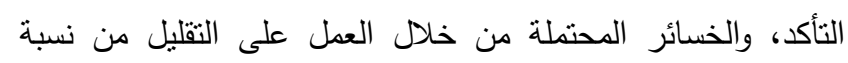

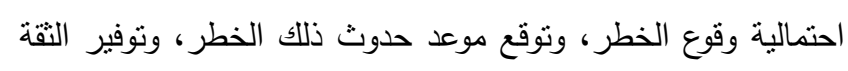

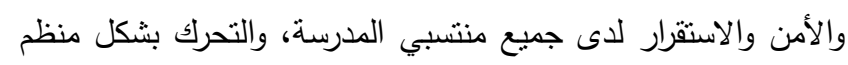

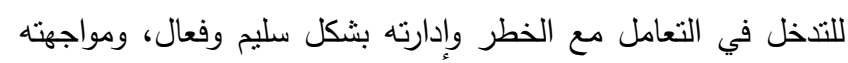

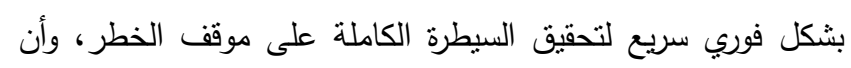




\begin{tabular}{|c|c|}
\hline \multicolumn{2}{|l|}{ الجدول (1): الخطر وآلية مواجهته. } \\
\hline آلية المواجهة & الخطر \\
\hline 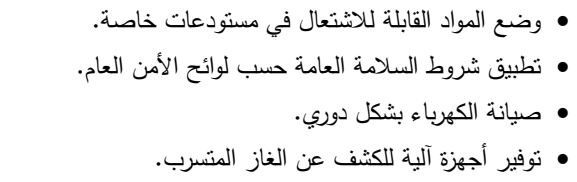 & مخاطر الأمن \\
\hline 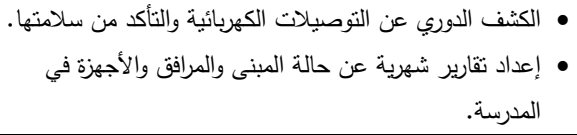 & مخاطر المباني \\
\hline • • • عمل نظفير برامج تدريبية لجميع العاملين في المدرسة. & المخاطر البشرية \\
\hline • • • توفير البرامج التنريبية لتطوير عمل المعلمين. & المخاطر ضعفى التعليمي \\
\hline
\end{tabular}

المصدر(11): تصور مقترح لإدارة المخاطر المدرسية في مصر في ضوء بعض الخبرات الأجنبية والعربية: دراسة مقارنة، دراسات تربوية واجتماعية،

.911-984، (4)21 (4) (4)

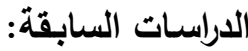

تم حصر بعض الدراسات السابقة التي تتاولت إدارة المخاطر

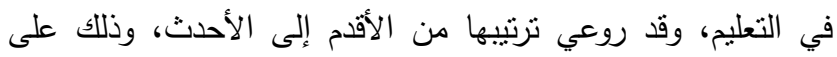
النحو الآتي: أجرى ارنرانجسيود(24) دراسة هدفت لتحليل إدارة الأزمات

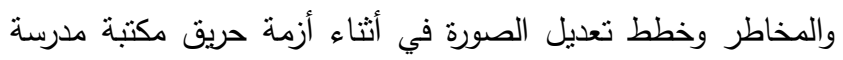
ماهيدول ويتاينسورن، وأثارت نتائج الدراسة إلى أن الاستراتيجيات

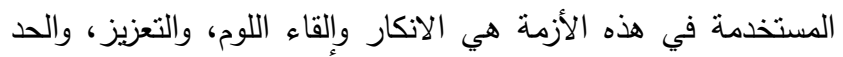

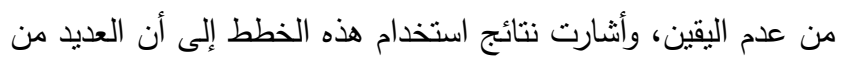

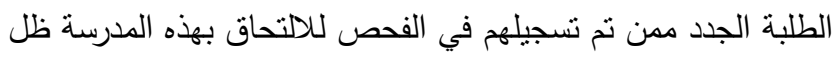
كما هو في السنوات الأخيرة. دراسة باتتاناجربان وآخرون(31) هدفت هذه الدراسة إلى تطوير نظام المعتمد، وتقييم مخرجات إدارة مخاطر المدارس الخاصة، التعليم

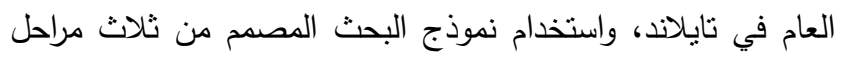

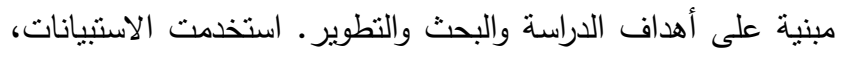

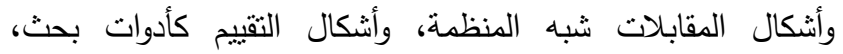
وتوصلت الدراسة إلى نتائج من أهمها أن المشكلات والعوامل الرئيسة في إدارة المخاطر المدرسية تنعكس في أربعة مجالات رئيسة: الاستراتيجية، والعملية، والتتفيذ المالي، وتطبيق الامتتال.

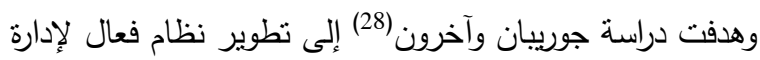
المخاطر في مدارس التعليم الخاص وفي التعليم العام في تايلاند، والعمل على تقييم المشكلات والوضع الحالي، وتطويرها لنظام لإدارة فئمان

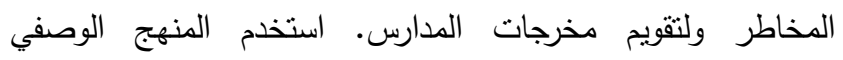
المسحي، وتكونت العينة من أربع مدارس، وأعدت الأداة (الاستبانة)،
السلامة والصحة في المباني الددرسية كالمخارج والمرات،

$$
\text { وسلالم الطوارئ وتجهيزات الأمن والسلامة. }
$$

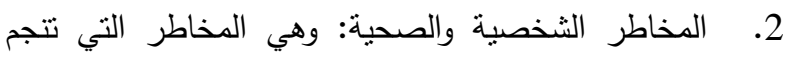

عن الأضرار التي تنتأ نتيجة عدم الاكتراث بتطبيق وهيق

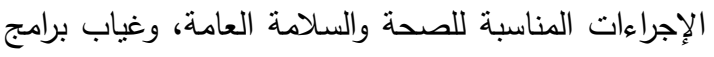

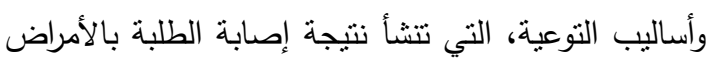

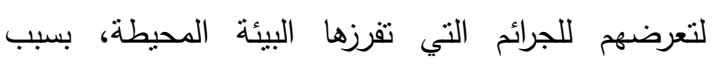
القصور في عملية توفير المرافق الصحية المناسبة كَمًا وكيفا، أو نتيجة نراكم النفايات بالبيئة المدرسية.

\section{دور الإدارة المدرسية في إدارة المخاطر :}

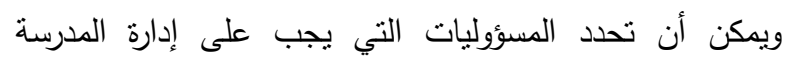

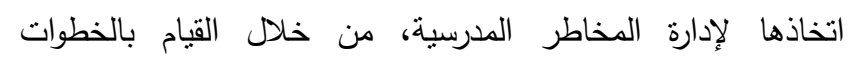
التالية(9)(17)( الخاذها

1. التخطيط: إذ يجب على إدارة المدرسة إعداد سيناريوهات للأحداث وتصورات عن الأخطار المتوقعة الحدوث والمحتملة، واتخاذ مجموعة من الإجراءات الفعالة والمناسبة

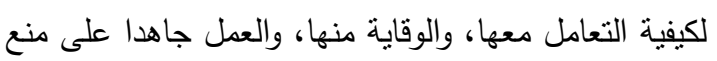

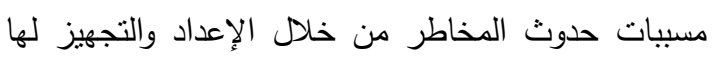
من فِبَلِ الفريق المشكّل لإدارة المخاطر في المدرسة. 2. التتظيم: لابد من توفر التسيق والتوافق والتكامل بين

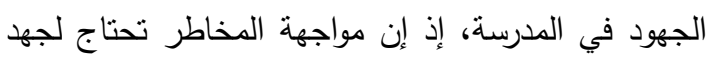

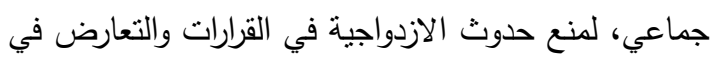

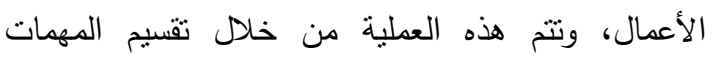
وإسنادها وتوزيعها على فريق إدارة المخاطر في الدرسة.

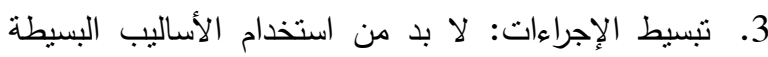

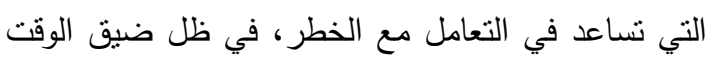

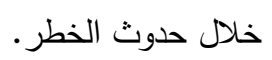

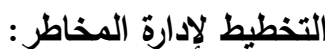

برى الباحثان أن إدارة المخاطر تبدأ بالمرحلة الوقائية وتثمل

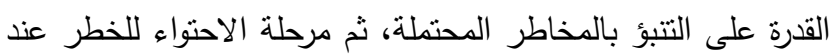

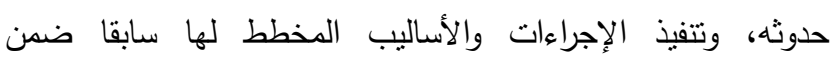
السياسات المحددة من قبل إدارة المدرسة، ثم مرحلة معالجة الآثار

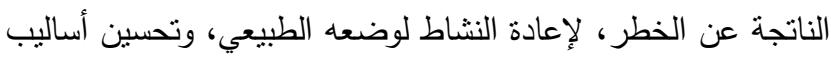

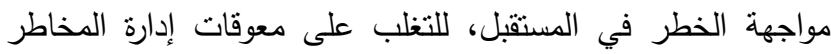

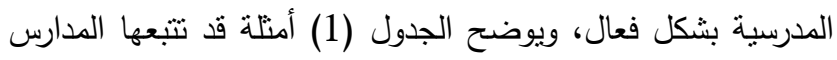

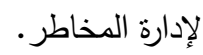


المؤهل العلمي ولصالح قادة المدارس من ذوي المؤهل (الدبلوم

(العالي).

\section{التعليق على الاراسـات السابقة:}

يرى الباحثان من خلال اسنطلاع الدراسات السابقة حول إدارة

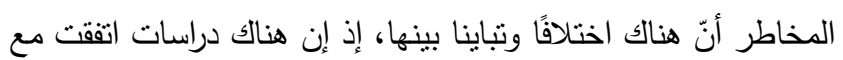
الدراسة الحالية، وبعضها اختلف وتم مناقثة هذه الدراسات من خلال أربع نقاط رئيسة هي: الأهداف، الأدوات، العينات، النتائج.

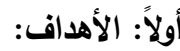

هدفت بعض الدراسات إلى تعرف أثر وفاعلية تطبيق إدارة

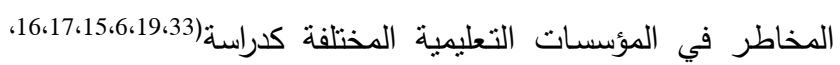

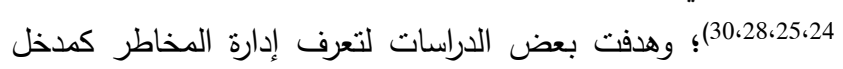

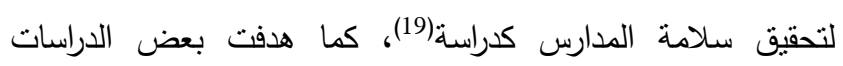

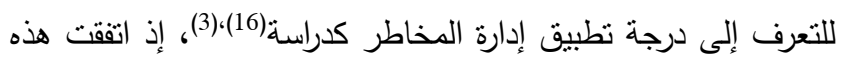

$$
\text { الدراسات مع هدف الدراسة الحالية. }
$$

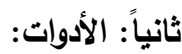

استخدمت بعض الدراسات أدوات من تطوير الباحث لتحقيق الادوات

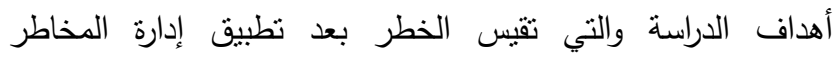

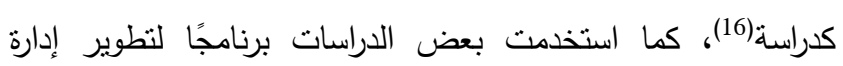
المخاطر كدراسة(28)، إذ استخدمت دراسة (6)، (30)، أدوات لجمع البيانات الوصفية تم تطويرها من قبلهم، وهذا ما تم في هذه الدراسة.

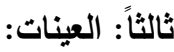

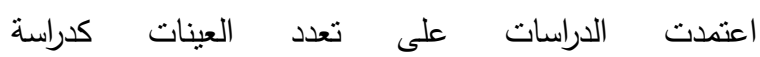
ودراسة(17،15،6،19،33،30،25،24)؛ إذ استخدمت بعض الدات الدراسات عينات

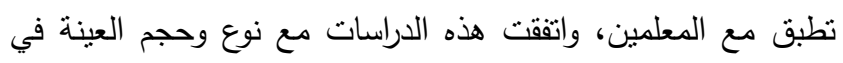

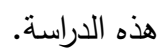

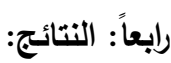

دلت نتائج بعض الدراسات على أن مستويات إدارة المخاطر

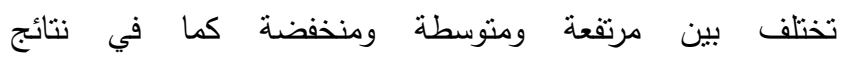
ودراسة(13)،(3)،(30)، (17).

وتأني الدراسة الحالية لتعرف واقع التخطيط لإدارة الدخاطر في

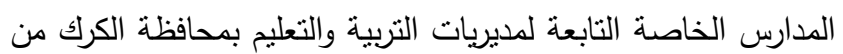
وجهة نظر المعلمين. وتركز الدراسة على متغيري (الخبرة، ومستوى المدرسة)،

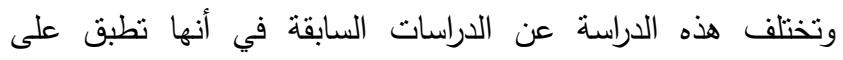

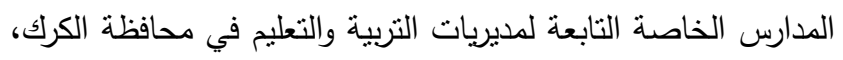

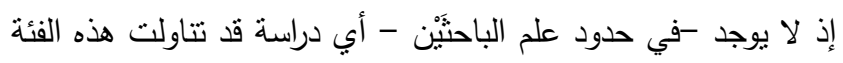

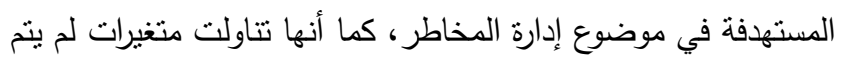

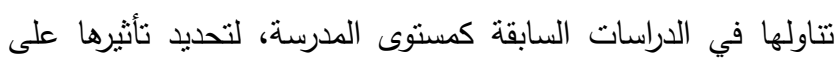

تم التأكد من صدق الأداة وثباتها، وأنشارت النتائج إلى أنه يمكن النظر

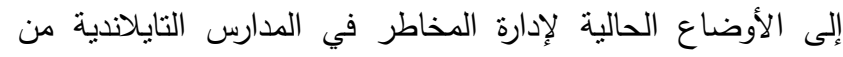

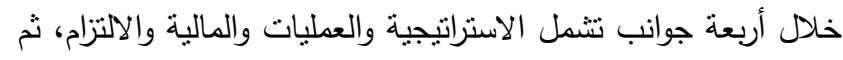

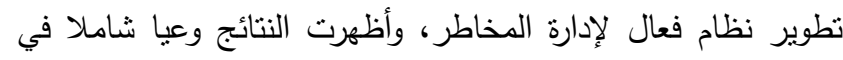
إدارة المخاطر وبدرجة مرتفعة بعد تتفيذ النظام المقترح.

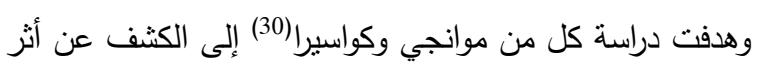

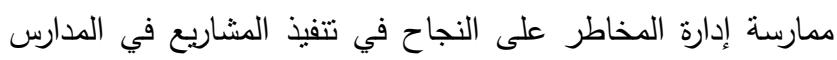
الثانوية في مقاطعة كيامبو في كينيا، استخدم في الدراسة الدنهي النهاج

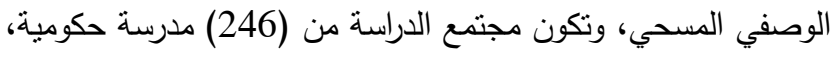
وتكونت عينة الدراسة من (74) مدرسة حكومية، وتم إعداد استبانة

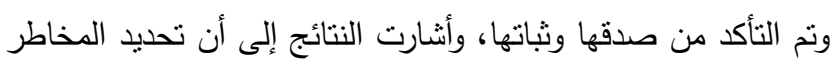

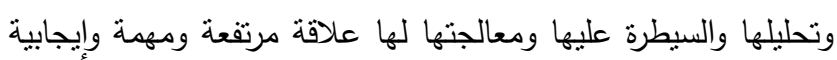
مع التنفيذ الناجح للمشاريع في هذه المدارس.

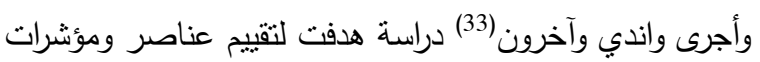
نظام إدارة المخاطر في الددارس الثنانوية في تايلاند، واقتراح

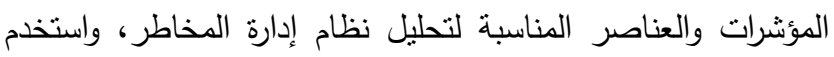
في الدراسة المنهج الوصفي المسحي، وتكونت العينة من (350) فردا، وتم إعداد استبانة وتم التأكد من صدق الكن الأداة وثباتها، وأنثارت

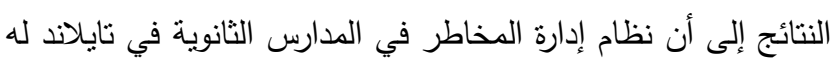

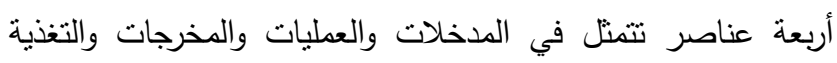

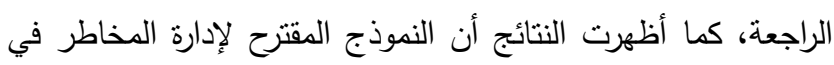
مدارس تايلاند متتاغم مع بياناتها التجربيية.

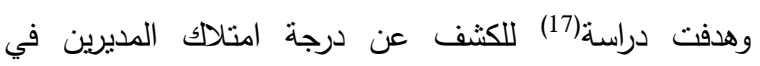
المدارس الحكومية في الزرقاء لمهارة إدارة المخاطر والأزمات

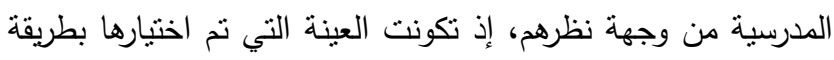

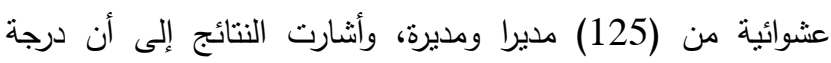
امتلاك المديرين في المدارس الحكومية التابعة لمحافظة الزرقاء لمهارة

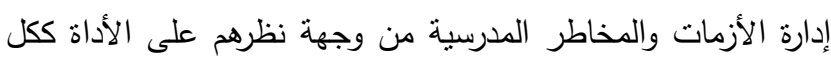

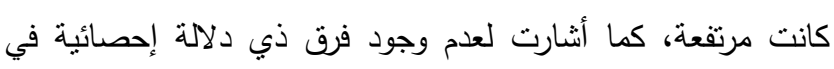

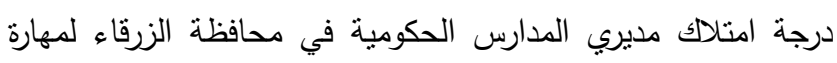
إدارة الأزمات تُعزى لمتغير الجنس.

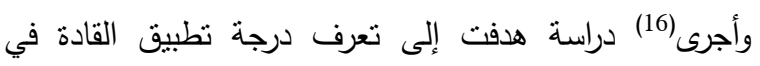

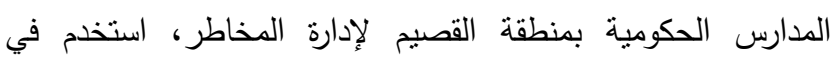
الدراسة المنهج الوصفي المسحي، ونكونت العينة من (456) قائدا، وتم إعداد الاستبانة، وبعد ذلك تم التأكد من صدقها وثنباتها، وأثنارت

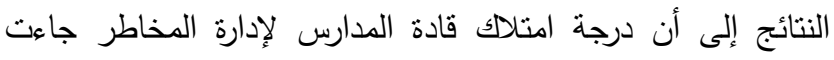

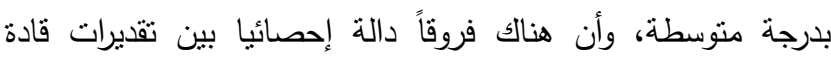

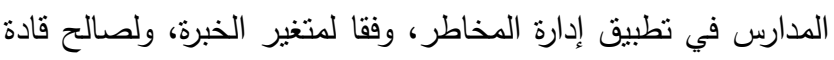

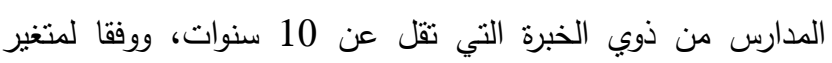


القدرة على تقييم المخاطر ومراجعتها (6) فقرات. وقد استخدم تدريج ليكرت الخماسي (أوافق بشدة، أوافق، محايد، لا أوافق، لا أوافق بشدة) في تدريج فقرات أداة الدراسة.

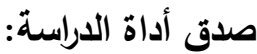

لتعرف صدق الأداة المعدة للاراسة نم استخدام صدق المحتوى، وذللك بعرضها على (10) مُحكّمين من المختصين بالإدارة التربوية، وتم الأخذ بآرائهم واقتراحاتهم وتعديلاتهم، حيث تُّم الابقاء على الفقرات

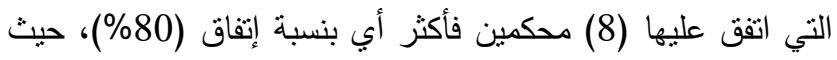
تم تعديل صياغة (5) فقرات، ولم يتم حذف أي فقرة.

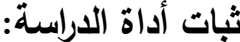

تم التحقق من ثبات الأداة بطريقة الاتساق الداخلي (كرونباخ

ألفا)، إذ نم تطبيق أداة الدراسة على عينة استطلاعية بلغت (25) معلماً ومعلمة تم اختبارهم بطريقة عشوائية من خارج عينة الدراسة، ثم تم إدخال البيانات إلى ذاكرة الحاسوب وتم استخراج معامل كرونباخ ألفا (Cronbach Alpha)، والجدول (3) يبين قيم الثبات حسب

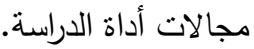

جدول (3): قيمة معامل الثبات للاتساق الداخلي لأبعاد أداة الدراسة.

\begin{tabular}{|c|c|}
\hline معامل الثبات (كرونباخ ألفا) & المجال \\
\hline 0.92 & الوعي بطبيعة المخاطر في المدرسة \\
\hline 0.83 & القدرة على مواجهة المخاطر \\
\hline 0.93 & القدرة على تشخيص المخاطر \\
\hline 0.86 & القدرة على اتخاذ القرار ومواجهة المخاطر \\
\hline 0.88 & القدرة على تقييم المخاطر ومراجعتها \\
\hline 0.94 & الأداة ككل \\
\hline
\end{tabular}

يبين الجدول (3) أن أداة الدراسة تتمتع بدرجات ثبات مقبولة

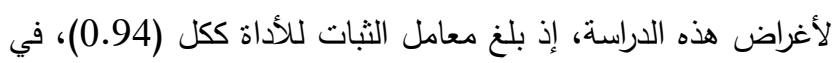
حين نزاوحت قيم معاملات الثبات على المجالات ( 0.83- 0.93).

\section{معيار الدكم على فقرات أداة الدراسة:}

استخدم المعيار التالي في الحكم على درجة الفقرات:

إذا كان الوسط الحسابي للفقرة أقل من أو بساوي (2.33)

$$
\text { تكون الدرجة منخفضة. }
$$

إذا كان الوسط الحسابي للفقرة محصورا بين (2.34-

$$
\text { 3.67) نكون الدرجة متوسطة. }
$$

إذا كان الوسط الحسابي للفقرة أكبر من أو يساوي (3.68)

$$
\text { تكون الدرجة مرتفعة. }
$$

$$
\text { عرض النتائجج: }
$$

فيما يلي عرض لنتائج الدراسة مرنبة وفقاً لأسئلتها:
مستوى إدارة المخاطر ، شملت المدارس الخاصة في محافظة الكرك، ومن هنا فإن هذه الدراسة تأني لسد شيء من النقص العملي في أدبيات إدارة المخاطر في المدارس. كما استفاد الباحثان من الدراسات السابقة في نطوير أداة الدراسة من خلال الاطلاع على الأدوات في الدراسـات السابقة وخطوات إعدادها وتطويرها، والإفادة من نقاط القوة في تلك الدراسات، وتفادي السلبيات التي وقع فيها الباحثّن في أثناء إجراء دراساتهم.

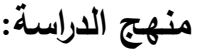

استخدمت الدراسة المنهج الوصفي المسحي لمناسبته أغراض هذه

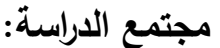

تكون مجتمع الدراسة من المعلمين والمعلمات العاملين في الددارس الخاصة التابعة لمديريات التربية والتعليم بمحافظة الكرك،

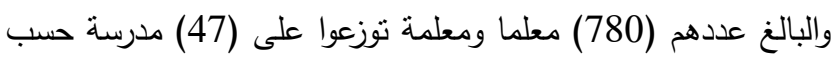
إحصائية (22).

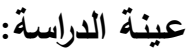

تألفت عينة الدراسة من (280) معلماً ومعلمة، نم اختيارهم بطريقة عشوائية بسيطة، وبعد استبعاد (8) استبانات لعدم الصلاحية

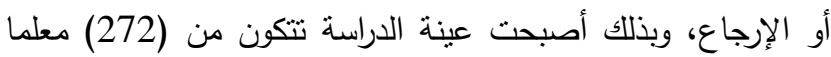
ومعلمة شكلوا ما نسبته (34.9\%) من مجتمع الدراسة. والجدول (1)

\begin{tabular}{|c|c|c|c|}
\hline النسبة & العدد & الوظيفة & المتغير \\
\hline$\% 74.3$ & 202 & أساسية & \multirow{3}{*}{ مستوى المدرسة } \\
\hline$\% 25.7$ & 70 & ثانوية & \\
\hline$\% 100$ & 272 & المجموع & \\
\hline$\% 69.5$ & 189 & أقل من عشر سنوات & \multirow{3}{*}{ 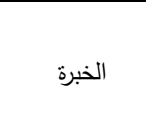 } \\
\hline$\% 30.5$ & 83 & عشر سنوات فأكثر & \\
\hline$\% 100$ & 272 & المجموع & \\
\hline
\end{tabular}
يبين توزيع أفراد عينة الدراسة وفقا لـتغيري الدراسة (مستوى المدرسة،

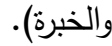

جدول (2): توزيع أفراد عينة الدراسة وفقا لمتفيري مستوى المدرسة، والخبرة.

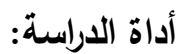

تم تطوير أداة الدراسة من خلال الاطلاع على الأدب النظري ومراجعة الدراسات السابقة ذات الصلة بموضوعها مثل دراسة(11)،(15)، والتي نكونت بشكلها الأولي من (30) فقرة، وقد توزعت على خمسة

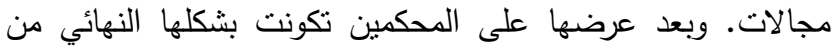
(30) فقرة، توزعت على خمسة مجالات هي: مجال الوعي بطبيعة المخاطر في الددرسة (6) فقرات، ومجال القدرة على مواجهة المخاطر (5) فقرة، ومجال القدرة على تتخيص المخاطر (6) فقرات، ومجال القدرة على اتخاذ القرار ومواجهة الهخاطر (7) فقرات، ومجال 
الخامسة "تتعرض مدرسني لمخاطر داخلية (تصدع البناء المدرسي، والحرائق، وتسرب مواد من المختبرات، والعنف المدرسي، وإضراب المعلمين أو الطلبة الخ)" وبدرجة منوسطة. جدول (5): الأوساط الحسابية والانحرافات المعيارية والرتبة والارجة لفقرات مجال الوعي بطبيعة المخاطر في المدرسة.

\begin{tabular}{|c|c|c|c|c|c|}
\hline اللارجة & الرتبة & المعياري & الوسابي & محتوى الفقرة & رقفر \\
\hline متوسطة & 1 & 1.24 & 3.33 & يتم تداول كلمة خطر في البيئة الداخلية & 1 \\
\hline متوسطة & 2 & 1.27 & 3.08 & 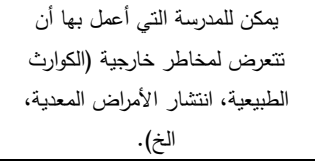 & 6 \\
\hline متوسطة & 3 & 1.33 & 2.94 & تتعرض مدرستي لمخاطر تصنف أنها & 3 \\
\hline منوسطة & 4 & 1.32 & 2.92 & تشكل بيئة عمل المدرسة التي أعمل بها & 2 \\
\hline متوسطة & 5 & 1.32 & 2.91 & المؤثر المخاطر التي تتعرض لـها ألتي أعمل بها على أدائها & 4 \\
\hline متوسطة & 6 & 1.34 & 2.85 & 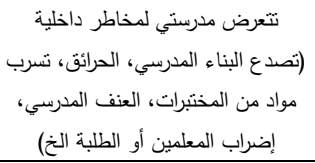 & 5 \\
\hline متوسطة & - & 1.11 & 3.00 & مجال " الوعي بطبيعة المخاطر في & $6-1$ \\
\hline
\end{tabular}

\section{2. مجال القرة على مواجهة المخاطر:}

تم حساب الأوساط الحسابية والانحرافات المعيارية لفقرات مجال القدرة على مواجهة المخاطر والجدول (6) يبين هذه النتائج.

جدول (6): الأوساط الحسابية والانحرافات المعيارية والرتبة والارجة لفقرات مجال القدرة على مواجهة المخاطر .

\begin{tabular}{|c|c|c|c|c|c|}
\hline الدارجة & 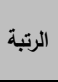 & المعياري - الماف & الحسابي & محتوى الفقرة & رقفم \\
\hline مرتفعة & 1 & 1.06 & 3.77 & يوجد كادر بشري مؤهل وكاف لعملية إدارة & 8 \\
\hline مرتفعة & 2 & 1.08 & 3.67 & لدلى مواجهة الدخاطرة المدرسة التي أعمل بها القدرة & 7 \\
\hline متوسطة & 3 & 1.12 & 3.65 & توفر إدارة مدرستي الاستراتيجيات اللازمة الإداطر التي قدارة لتعرض لها. & 10 \\
\hline متوسطة & 4 & 1.14 & 3.64 & يتوافر في مدرسني خطة معلنة لإدارة & 11 \\
\hline متوسطة & 5 & 1.19 & 3.56 & تمتلك مدرستي الموارد المالية الكافية & 9 \\
\hline متوسطة & - & 0.92 & 3.66 & مجال القدرة على مواجهة المخاطر ككل & $11-7$ \\
\hline
\end{tabular}

يبين الجدول (6) أن الوسط الحسابي لمجال القدرة على مواجهة المخاطر بلغ (3.66) وتعد هذه الدرجة منوسطة. وقد احتلت الفقرة الثامنة والتي تتص على "يوجد كادر بشري مؤهل وكافٍ لعملية إدارة المخاطر في الددرسة التي أنتمي إليها" المرتبة الأولى وبدرجة مرتفعة، وفي المرتبة الثانية جاءت الفقرة السابعة "لدى إدارة المدرسة التي لإلي أعمل بها القدرة على مواجهة المخاطر التي قد تتعرض لها" بدرجة التهانية

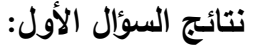

للإجابة عن سؤال الدراسة الأول الذي نص على: "ما واقع التخطيط لإدارة المخاطر في المدارس الخاصة التابعة لمديريات التربية والتعليم بمحافظة الكرك من وجهة نظر المعلمين؟" نم استخدام الأوساط الحسابية والانحرافات المعيارية لمجالات أداة الدراسة ولفقراتها، والجدول (4) يبين قيم الأوساط الحسابية والانحرافات المعيارية والرتبة والدرجة لمجالات أداة واقع التخطيط لإدارة المخاطر في المدارس الخاصة.

جدول (4): الأوساط الحسابية والاتحرافات المعيارية والرتبة واللرجة لواقع التخطيط لإدارة المخاطر في المدارس الخاصة ككل ولمجالاته في محافظة الكرك.

\begin{tabular}{|c|c|c|c|c|c|}
\hline 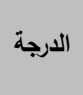 & 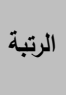 & المعياري & الحسابي & 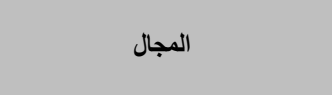 & 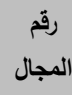 \\
\hline 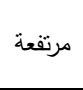 & 1 & 0.85 & 3.76 & القدرة على اتخاذ القرار ومواجهة & 4 \\
\hline 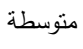 & 2 & 0.92 & 3.66 & القدرة على مواجهة المخاطر & 2 \\
\hline متوسطة & 3 & 0.91 & 3.63 & القدرة على تشخيص المخاطر & 3 \\
\hline 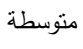 & 4 & 0.88 & 3.56 & القدرة على تقييم المخاطر ومراجعتها & 5 \\
\hline متوسطة & 5 & 1.11 & 3.00 & الوعي بطبيعة المخاطر في المدرسة & 1 \\
\hline متوسطة & - & 0.69 & 3.53 & واقع التخطيط ككل & \\
\hline
\end{tabular}

يبين الجدول (4) أن الوسط الحسابي لواقع التخطيط لإدارة

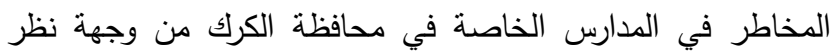

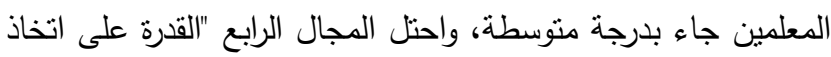
القرار ومواجهة المخاطر" المرتبة الأولى وبدرجة مرتفعة، وفي المرتبة

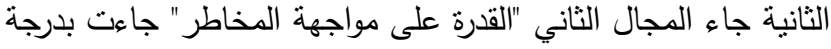
متوسطة، وبالمرتبة الأخيرة جاء المجال الأول "الوعي بطبيعة الكاءل

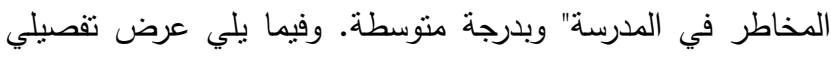
لواقع التخطيط لإدارة الدخاطر في المدارس الخاصة التابعة لدديريات التربية والتعليم بمحافظة الكرك من وجهة نظر المعلمين كما يلي:

\section{1. مجال الوعي بطبيعة المخاطر في المدرسة:}

تم حساب الأوساط الحسابية والانحرافات المعيارية لفقرات مجال الوعي بطبيعة المخاطر في المدرسة والجدول (5) يبين هذه النتائج. ينتين من الجدول (5) أن الوسط الحسابي لمجال الوعي بطبيعة الدخاطر في المدرسة بلغ (3.00) وتعد هذه الدرجة منوسطة، وقد

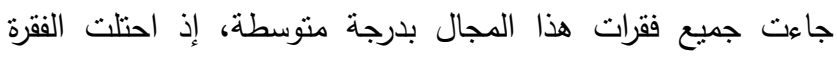
الأولى والتي تتص على: "يتم تداول كلمة خطر في البيئة الداخلية للمدرسة التي أعمل بها" المرتبة الأولى وجاءت بدرجة متوسطة، لألاكل وجاءت في المرتبة الثانية الفقرة السادسة "يمكن للمدرسة التي أعمل التل

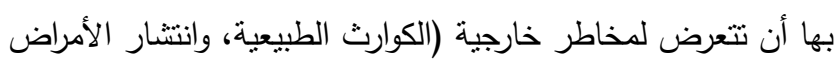

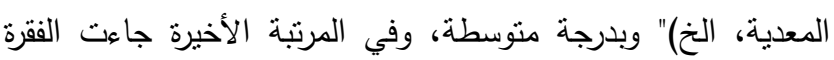


الرابعة والعشرون "تضع إدارتي سيناريوهات محدة لإدارة المخاطر في المدرسة التي أعمل بها" وبدرجة مرتفعة.

جدول (8): الأوساط الحسابية والاتحرافات المعيارية والرتبة واللارجة لفقرات مجال القدرة على اتخاذ القرار ومواجهة المخاطر.

\begin{tabular}{|c|c|c|c|c|c|}
\hline الدرجة & الرتبة & المعياري & التسابي & محتوى الفقرة & رقمة \\
\hline مرتفعة & 1 & 1.05 & 3.81 & تتخذ الإدارة في مدرسني القرار & 22 \\
\hline مرتفعة & 2 & 1.05 & 3.80 & يتم في مدرستي دراسة بدائل & 21 \\
\hline مرتفعة & 3 & 1.08 & 3.77 & تضع إدارة المدرسة التي أعمل المتراتيجية واضحة لإدارة & 20 \\
\hline مرتفعة & 4 & 1.07 & 3.76 & تحليل إدارة المدرسة التي أعمل المخاطر التي تتعرض لها & 18 \\
\hline مرتفعة & 4 & 1.11 & 3.76 & مدرستي على اختلاف مستوياتهم العاملين في & 23 \\
\hline مرتفعة & 6 & 1.03 & 3.71 & تأثوم إدارة مدرسني باستكثاف المخاطر على الوظائف & 19 \\
\hline مرتفعة & 7 & 1.03 & 3.68 & تضإدارة إدخاطر في المديناريوهات محددة التئ & 24 \\
\hline مرتفعة & - & 0.85 & 3.76 & مجال" القدرة على اتخاذ القرار & $24-18$ \\
\hline
\end{tabular}

\section{5. مجال القدرة على تقييم المخاطر ومراجعتها:}

نم حساب الأوساط الحسابية والانحرافات المعيارية لفقرات مجال القدرة على تقييم المخاطر ومراجعتها والجدول (9) يبين هذه النتائج. جدول (9): الأوساط الحسابية والانحرافات المعيارية والرتبة واللرجة لفقرات مجال

القدرة على تقييم المخاطر ومراجعتها.

\begin{tabular}{|c|c|c|c|c|c|}
\hline الدرجة & الرتبة & المعياري & الوسابي & محتوى الفقرة & رقمتم \\
\hline مرتفعة & 1 & 1.05 & 3.74 & 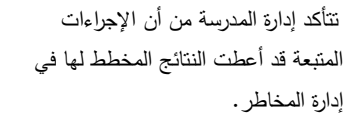 & 25 \\
\hline متوسطة & 2 & 1.08 & 3.62 & تُعِدُ إدارة المخاطر في مدرستي تقارير توضح & 26 \\
\hline متوسطة & 3 & 1.13 & 3.61 & تخوم إدارة المدرسة بعطلية تقييم ومراجعة & 27 \\
\hline متوسطة & 4 & 1.12 & 3.51 & 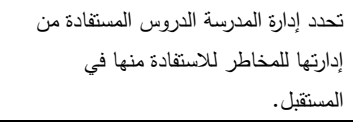 & 28 \\
\hline متوسطة & 5 & 1.17 & 3.47 & للطور إدارة المدرسة نظامها المعرفي في صناعة قرارات أفضل لمواجهة & 29 \\
\hline متوسطة & 6 & 1.22 & 3.41 & المخرض إدارة المدرسة تقريرها النهائي لإدارة & 30 \\
\hline متوسطة & - & 0.88 & 3.56 & مجال" القدرة على تقييم المخاطر ومراجعتها" & $30-25$ \\
\hline
\end{tabular}

مرتفعة، وفي المرنبة الأخيرة جاءت الفقرة التاسعة "تثنلك مدرستي الموارد المالية الكافية لمواجهة المخاطر وادارتها" وبدرجة منوسطة.

\section{3. مجال القدرة على تشخيص المخاطر:}

تم حساب الأوساط الحسابية والانحرافات المعيارية لفقرات مجال القدرة على نشخيص المخاطر والجدول (7) يبين هذه النتائج. جدول (7): الأوساط الحسابية والانحرافات المعيارية والرتبة واللارجة لفقرات مجال القدرة على تثخيص المخاطر .

\begin{tabular}{|c|c|c|c|c|c|}
\hline الدرجة & الرتبة & المعياري & الوسابي & محتوى الفقرة & الفقرة \\
\hline مرتنعة & 1 & 1.12 & 3.72 & 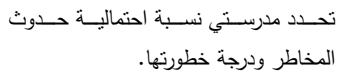 & 14 \\
\hline متوسطة & 2 & 1.11 & 3.65 & 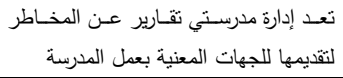 & 17 \\
\hline متوسطة & 3 & 1.06 & 3.63 & 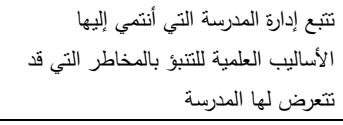 & 12 \\
\hline متوسطة & 4 & 1.08 & 3.62 & 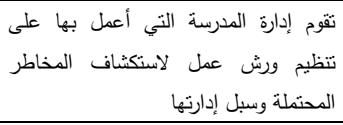 & 13 \\
\hline متوسطة & 5 & 1.14 & 3.59 & 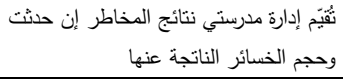 & 16 \\
\hline متوسطة & 6 & 1.09 & 3.58 & تكنها من تثخيص المخارة المدرسة التي أعل بها دراسات & 15 \\
\hline متوسطة & - & 0.91 & 3.63 & مجال "القرة على تشخيص وتقييم & $17-12$ \\
\hline
\end{tabular}

يبين الجدول (7) أن الوسط الحسابي لهجال القدرة على تتخيص الهخاطر بلغ (3.63) وتعد هذه الدرجة متوسطة. وقد احتلت الفقرة الرابعة عشرة والتي تتص على "تحدد مدرستي نسبة

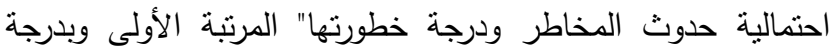
مرتفعة، وفي المرتبة الثانية جاءت الفقرة السابعة عشر "تعد إدارة مدرستي تقارير عن المخاطر لتقبيمها للجهات المعنية بعمل المدرسة" وبدرجة متوسطة، وفي المرنبة الأخيرة جاءت الفقرة "تجري إدارة المدرسة التي أعمل بها دراسات تمكنها من تشخيص المخاطر المحتملة" وبدرجة متوسطة.

\section{4. مجال القدرة على اتخاذ القرار ومواجهة المخاطر :} تم حساب الأوساط الحسابية والانحرافات المعيارية لفقرات مجال القدرة على اتخاذ القرار ومواجهة المخاطر والجدول (8) يبين هذه النتائج.

يبين الجدول (8) أن الوسط الحسابي لهجال القدرة على اتخاذ القرار ومواجهة الدخاطر بلغ (3.76) وتعد هذه الدرجة مرتفعة. وقد جاءت جميع فقرات هذا المجال بدرجة مرتفعة، واحتلت الفقرة الثانية والعشرون والتي تتص على "تتخذ الإدارة في مدرستي القرار المناسب التبال لمواجهة المخاطر" المرتبة الأولى، وفي المرتبة الثانية جاءت الفقرة

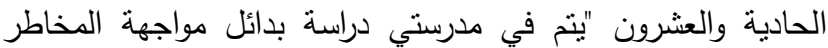
(تحملها، تتويعها، تجنبها، تحويلها)"، وفي المرتبة الأخيرة جاءت الفقرة 
المدارس الخاصة في محافظة الكرك من وجهة نظر المعلمين تبعا لمتغير الخبرة، حيث بلغت قيمة (ت) (0.546) وهي قيمة غير دالة إحصائيا. وكذلك لا توجد فروق ذات دلالة إحصائية في المجالات

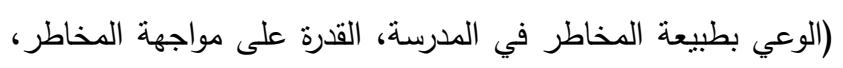
القدرة على تشخيص وتقييم المخاطر، القدرة على اتخاذ القرار ومواجهة المخاطر، القدرة على تقييم المخاطر ومراجعتها) تُعزى لتهى للخبرة، حيث كانت قيم (ت) غير دالة إحصائياً.

\section{نتائج السؤال الثالث: - (الث:}

للإجابة عن سؤال الدراسة الثالث: "هل توجد فروق ذات دلالة

إحصائية عند مستوى دلالة (a=0.05) بين منتسطات استجابة أفراد عينة الدراسة لواقع التخطيط لإدارة المخاطر في المدارس الخاصة التابعة لمديريات التربية والتعليم بمحافظة الكرك من وجهة نظر المعلمين تُعزى لمتغير مستوى المدرسة؟" تمت الإجابة عن هذا السؤال كما بلي: تم حساب الأوساط الحسابية والانحرافات المعيارية لواقع التخطيط لإدارة المخاطر في المدارس الخاصة في محافظة الكرك من وجهة نظر المعلمين ومجالاته تبعا لمتغير مستوى المدرسة، ولبيان دلالة الفروق الإحصائية بين الأوساط الحسابية تم استخدام اختبار "ت" للعينات المستقلة (Independent samples T-test) والجدول (11) يبين هذه النتائج.

جذول (11): الأوساط الحسابية والانحرافات المعيارية لواقع التخطيط لإدارة المخاطر ومجالاته في المدارس الخاصة في محافظة الكرك من وجهة نظر المعلمين تبعاً لمتغير مستوى المدرسة.

\begin{tabular}{|c|c|c|c|c|c|c|}
\hline مستوى & الحرية & قيمة & المعياري & الوسطاب & المدرسة & المجال \\
\hline \multirow[b]{2}{*}{0.756} & \multirow[b]{2}{*}{270} & \multirow[b]{2}{*}{0.312} & 1.09 & 3.02 & أساسية & \multirow{2}{*}{ الوالمي بطبيعة } \\
\hline & & & 1.18 & 2.97 & ثانوية & \\
\hline \multirow{2}{*}{0.638} & \multirow{2}{*}{270} & \multirow{2}{*}{0.47} & 0.88 & 3.67 & أساسية & \multirow{2}{*}{ مواجهة الدخاطر } \\
\hline & & & 1.02 & 3.61 & ثانوية & \\
\hline \multirow[b]{2}{*}{0.099} & \multirow[b]{2}{*}{270} & \multirow[b]{2}{*}{1.65} & 0.85 & 3.69 & أساسية & \multirow{2}{*}{ تشخيص وتقييم القدرة على } \\
\hline & & & 1.06 & 3.48 & ثانوية & \\
\hline \multirow[b]{2}{*}{0.504} & \multirow[b]{2}{*}{270} & \multirow[b]{2}{*}{0.67} & 0.83 & 3.78 & أساسية & \multirow{2}{*}{ القرار ومواجهة الخاذ } \\
\hline & & & 0.92 & 3.70 & ثانوية & \\
\hline \multirow{2}{*}{0.767} & \multirow{2}{*}{270} & \multirow{2}{*}{0.68} & 0.87 & 3.55 & أساسية & \multirow{2}{*}{ القدرة على تقييم } \\
\hline & & & 0.90 & 3.59 & ثانوية & \\
\hline \multirow{2}{*}{0.454} & \multirow{2}{*}{270} & \multirow{2}{*}{0.750} & 0.65 & 3.54 & أساسية & \multirow{2}{*}{ واقع النخطيط } \\
\hline & & & 0.79 & 3.47 & ثانوية & \\
\hline
\end{tabular}

يبين الجدول (11) أنه لا توجد فروق ذات دلالة إحصائية في الأوساط الحسابية في الدرجة الكلية لواقع التخطيط لإدارة المخاطر في لإني المدارس الخاصة في محافظة الكرك من وجهة نظر المعلمين تبعا
يبين الجدول (9) أن الوسط الحسابي لمجال القدرة على تقييم المخاطر ومراجعتها بلغ (3.56) وتعد هذه الدرجة متوسطة. واحتلت

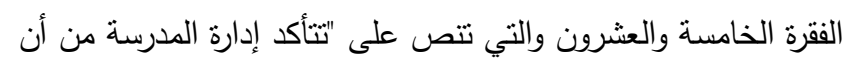
الإجراءات المتبعة قد أعطت النتائج المخطط لها في إدارة المخاطر" المرتبة الأولى وبدرجة مرتفعة، وفي المرتبة الثانية جاءت الفقرة السادسة والعشرون "تعد إدارة المخاطر في مدرستي تقارير توضح خطر الانحرافات المتبقية" وبدرجة متوسطة، وفي المرتبة الأخيرة جاءت الفقرة الثلاثثن "تعرض إدارة المدرسة تقريرها النهائي لإدارة المخاطر على جميع الأطراف المعنية بشؤون المدرسة" وبدرجة متوسطة. نتائج السؤال الثاني:

للإجابة عن سؤال الدراسة الثاني: "هل نوجد فروق ذات دلالة إحصائية عند مستوى دلالة (م=0.05) بين متوسطات استجابة أفراد

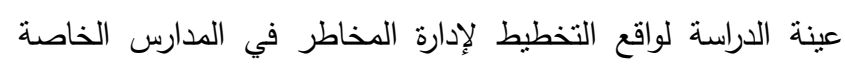

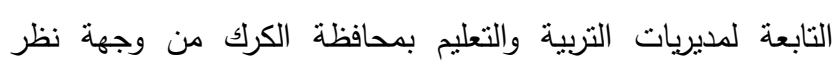
المعلمين تُعزى لمتغير الخبرة؟" تمت الإجابة عن هذا السؤال كما يلي:

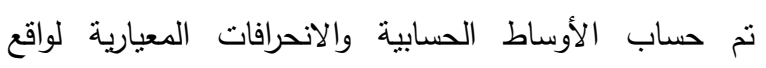
التخطيط لإدارة المخاطر في المدارس الخاصة في محافظة الكرك من وجهة نظر المعلمين ومجالاته تبعا لمتغير الخبرة، ولبيان دلالة الفروق الإحصائية بين الأوساط الحسابية تم استخدام اختبار "ت" للعينات المستقلة (Independent samples T-test) والجدول (10) يبين هذه النتائج.

جدول (10): الأوساط الحسابية والانحرافات المعيارية لواقع التخطيط لإدارة المخاطر ومجالاته في المدارس الخاصة في محافظة الكرك من وجهة نظر المعلمين تبعاً لمتغير الخبرة.

\begin{tabular}{|c|c|c|c|c|c|c|}
\hline مستوى & الحرية & قيمة & الانحراف & الوسابي & الخبرة & المجال \\
\hline \multirow[b]{2}{*}{0.330} & \multirow[b]{2}{*}{270} & \multirow[b]{2}{*}{0.929} & 1.07 & 2.96 & أقل من عشر سنوات & \multirow{2}{*}{ المخاطر في بطبيعة } \\
\hline & & & 1.21 & 3.10 & عشر سنوات فأكثر & \\
\hline \multirow{2}{*}{0.402} & \multirow{2}{*}{270} & \multirow{2}{*}{0.840} & 0.93 & 3.69 & أقل من عشر سنوات & \multirow{2}{*}{ مواجهة المخاطر على } \\
\hline & & & 0.89 & 3.59 & عشر سنوات فأكثر & \\
\hline \multirow{2}{*}{0.651} & \multirow{2}{*}{270} & \multirow{2}{*}{0.453} & 0.90 & 3.62 & أقل من عشر سنوات & \multirow{2}{*}{ تشخيص وتقييم القدرة على } \\
\hline & & & 0.92 & 3.67 & عشر سنوات فأكثر & \\
\hline \multirow{2}{*}{0.416} & \multirow{2}{*}{270} & \multirow{2}{*}{0.815} & 0.85 & 3.73 & أقل من عشر سنوات & \multirow{2}{*}{ القرار ومواجهة القداذ } \\
\hline & & & 0.87 & 3.82 & عشر سنوات فأكثر & \\
\hline \multirow{2}{*}{0.793} & \multirow{2}{*}{270} & \multirow{2}{*}{0.262} & 0.86 & 3.55 & أقل من عشر سنوات & \multirow{2}{*}{ القدرة على تقييم } \\
\hline & & & 0.92 & 3.58 & عشر سنوات فأكثر & \\
\hline \multirow{2}{*}{0.586} & \multirow{2}{*}{270} & \multirow{2}{*}{0.546} & 0.70 & 3.51 & أقل من عشر سنوات & \multirow{2}{*}{ واقع التخطيط } \\
\hline & & & 0.69 & 3.56 & عشر سنوات فأكثر & \\
\hline
\end{tabular}

بيين الجدول (10) أنه لا توجد فروق ذات دلالة إحصائية في الأوساط الحسابية في الدرجة الكلية لواقع التخطيط لإدارة المخاطر في 
الخاصة بشكل خاص ضمن البيئة الداخلية لهذه المدارس، لشعور المعلمين بإمكانية حدوث المخاطر الخارجية والداخلية في أي وقت مثل الزلازل وانتشار الأمراض والحرائق والعنف المجتمعي والطلابي والذي قد يمسّ المدرسة بأي شكل من الأشكال.

أما ما يتعلق بمجال القدرة على مواجهة المخاطر فقد جاء

بالمرتبة الثانية وبدرجة متوسطة، وقد يُعزى ذلك إلى توفر أشخاص ئسل مؤهلين في المدارس الخاصة التابعة لمديريات التربية والتعليم بمحافظة الكرك لإدارة المخاطر التي قد تواجه هذه المدارس، والتي تتصف بصغر حجمها وقلة عدد الطلبة فيها مقارنة مع المدارس الحكومية، وقد تُعزى النتيجة المتوسطة إلى أن المخاطر التي قد تواجه هذه المدارس قد نكون قليلة وفيها جانب من الندرة خاصة انها ضمن بيئة اجتماعية تتصف بأنها متماسكة ومترابطة مقارنة مع المدن الكبرى بالمملكة.

\section{أما مجال القدرة على تثخيص المخاطر فقد جاء بالمرنبة}

الثالثة من وجهة نظر عينة الدراسة وبدرجة منوسطة وقد يُعزى ذلك هـ إلى أن تأهيل مديري المدارس في مجال نتخيص المخاطر التي قد تواجه مدارسهم وتقييمهم لها دون المستوى المطلوب لعدم حصولهم على التدريب والتأهيل في هذا المجال من قبل أثخاص متخصصين ،خاصةً أن هذا الجانب يعد من المفاهيم الحديثة نوعا ما في المجال التربوي وخاصة في إدارة المدارس، وقد يُعزى إلى ضعف الإدارات في إجراء الدراسات التي تُكّنها من تشخيص المخاطر والتتبؤ بحدوثها

$$
\text { وبحجم الخسائر الناتجة عنها. }
$$

أما مجال القدرة على اتخاذ القرار ومواجهة المخاطر فقد جاء بالمرتبة الأولى وبدرجة مرتفعة. وقد يُعزى ذلك إلى أن إدارات

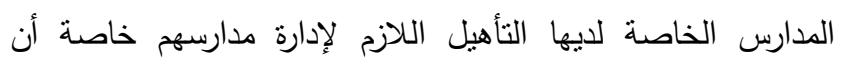
التعاقد مع مديري هذه المدارس يتم على أساس الكفاءة والقدرة والخبرة في إدارة المدرسة بشكل عام وغالبا ما تكون هذه الفئة من مديري

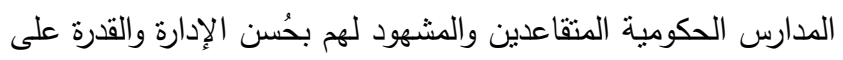
اتخاذ القرارات.

أما مجال القدرة على تقييم المخاطر ومراجعتها فقد جاء بالمرتبة الرابعة وبدرجة متوسطة، وقد يُعزى ذلك إلى أن إدارة المدرسة

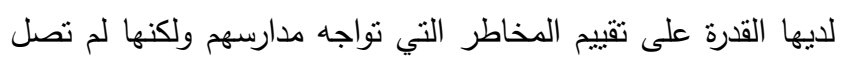
إلى المستوى المتوقع، فهي نتأكد من اتباع الإجراءات المعتمدة في خطة إدارة المخاطر وتوضح من خلال التقارير التي تعدها الانحرافات عن هذه الخطط لتقوم بمراجعتها والاستفادة من هذه التجارب في تعديل خطة إدارة المخاطر وفقا لنتائج التقارير التي أعدها فريق إدارة

$$
\text { المخاطر في المدرسة. }
$$

2. مناقتة النتائج المتعلقة بالسؤال الثاني والذي ينص على:

"هل توجد فروق ذات دلالة إحصائية عند مستوى دلالة

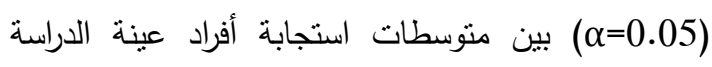

لمتغير مستوى المدرسة، حيث بلغت قيمة (ت) (0.750) وهي قيمة غير دالة إحصائيا. وكذللك لا توجد فروق ذات دلالة إحصائية عند مستوى الدلالة (10.05) في المجالات (الوعي بطبيعة المخاطر في المدرسة، القدرة على مواجهة المخاطر، القدرة على تشخيص وتقييم المخاطر ، القدرة على اتخاذ القرار ومواجهة المخاطر، القدرة على تقييم المخاطر ومراجعتها) تُعزى لمستوى المدرسة، كانت بلغت قيم (ت)، وهي قيم غير دالة إحصائياً.

\section{مناقشة النتائج:}

وفيما يلي مناقثنة النتائج وفقا لترتيب أسئلتها: 1. مناقتنة النتائج المتعلقة بالسؤال الأول والذي ينص على: "ما واقع التخطيط لإدارة المخاطر في المدارس الخاصة بلة التابعة لمديريات التربية والتعليم بمحافظة الكرك من وجهة نظر المعلمين؟" أثنارت النتائج المتعلقة بالسؤال الأول إلى أن واقع التخطيط لإدارة المخاطر في المدارس الخاصة التابعة لمديريات التزبية والتعليم بمحافظة الكرك من وجهة نظر المعلمبن كان بدرجة منوسطة، وقد جاء مجال القدرة على اتخاذ القرار ومواجهة المخاطر بالمرنبة الأولى منى وبدرجة مرتفعة، واحتل المرتبة الأخيرة مجال الوعي بطبيعة المخاطر في المدرسة وبدرجة منوسطة. وقد يعزو الباحثان هذه النتيجة إلى أن واقع التخطيط لإدارة المخاطر في المدارس الخاصة التابعة لمديريات التربية والتعليم بمحافظة الكرك من وجهة نظر المعلمين جاء دون المستوى المطلوب وذلك لاعتقاد بعضهم أن التخطيط لإدارة المخاطر

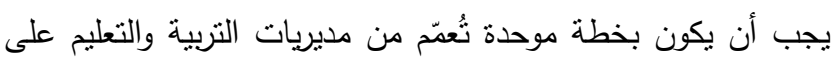

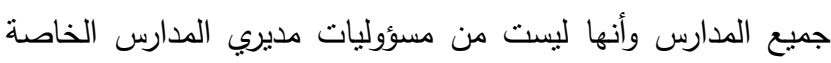
لعدم وجود أشخاص لديهم الدراية والمعرفة والقدرة على إعداد خطة مدئ لإدارة المخاطر التي قد تواجه مدارسهم، وجاء مجال القدرة على اتخاذ القرار ومواجهة المخاطر بالمرتبة الأولى وبدرجة مرتقعة. ويعزو الباحثان هذه النتيجة إلى أن معلمي المدارس الخاصة لديهم الثقة والشعور بمقدرة مديريهم على اتخاذ القرار ومواجهة المخاطر خاصة أن إداراتهم تعتمد على العمل بروح الفريق الواحد والعمل الجماعي في إدارة شؤون المدرسة بشكل عام والمخاطر بشكل خاص، وجاء مجال الوعي بطبيعة المخاطر في المدرسة بالمرتبة الأخيرة وبدرجة متوسطة، وقد تُعزى هذه النتيجة إلى عدم وجود أسس ومعايير للحكم على طبيعة المخاطر التي قد تواجه المدارس ولعدم وجود دورات ثنقيفية وتوعوية بطبيعة المخاطر التي تواجه المدارس لذا جاء هذا المجال دون المستوى المتوقع، وتتفق نتائج هذه الدراسة مع دراسة(6)،(15). أما ما يتعلق بمجال الوعي بطبيعة المخاطر في المدرسة وتئة والذي جاء بدرجة منوسطة وبالمرتبة الأخيرة، فقد يُعزى ذلك إلى أن كلمة "خطر" يتم تداولها في المدارس بشكل عام وفي المدارس 
لإدارة المخاطر منتابهةً بغض النظر عن مستوى الدرسة التي ينتمون إليها، وتتفق هذه النتيجة مع دراسة(27).

$$
\text { التوصيات: }
$$

$$
\text { بناءً على نتائج الدراسة يوصي الباحثان بما يأني: }
$$

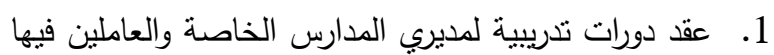

لتوضيح مفهوم التخطيط لإدارة المخاطر وكيفية تطبيقه في

$$
\text { الواقع. }
$$

2. ت تنظيم برامج نوعوية وتثقيفية عن التخطيط لإدارة المخاطر في المدارس الخاصة في محافظة الكرك.

3. إجراء دراسة مسحية مقارنة عن التخطيط لإدارة المخاطر

$$
\text { في الددارس الحكومية والخاصة وعلى مستوى المملكة. }
$$

\section{References:}

1. Bouzidi, Khaleda (2009). Risk Management in Small and Medium Enterprises Case Study: Limited Shredding companies for Public Services and Merchants (DOUDAH), unpublished Master Thesis, University of Mohamed Bougara Boumerdes, People's Democratic Republic of Algeria.

2. Jad Allah, Mahmoud (2012). Management of Educational Crises in Schools. Cairo: Dar Al-Fikr Al-Arabi.

3. Al-Juhani, Abdullah (2018). "Methods to Develop the Ability of School Leaders to Make Decisions in Managing School Crises". Education and Psychology Studies, 1 (60), 45-64.

4. Radwan, Imad (2013). Educational Crises Management and Ways of Confrontation. Cairo: The Egyptian General Books Authority, Egypt.

5. Raheef, Almosaad (2015). "Banking Risk Management and the Extent to which Iraqi Banks Adhere to Basel 2 Requirements: An Applied Study in Rashid and the Middle East". Journal of the Baghdad University College of Economics, 1 (46), 398- 420.

6. Al-Zubaidi, Rabab (2014). "Managing Risks in the Private University Colleges of Baghdad Governorate from the Viewpoint of Heads of Teaching Departments". Unpublished Master Thesis, University of Baghdad.

7. Zaki, Ahmed (2016). "The Expected Role of the General Administration of Education towards School Crises in Al-Ahsa Governorate from the Viewpoint of Middle and High School Principals", Security Research Magazine, 25 (63), 267_289.
لواقع التخطيط لإدارة المخاطر في الدارس الخاصة التابعة

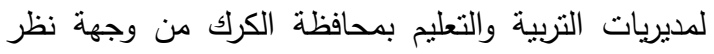

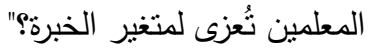

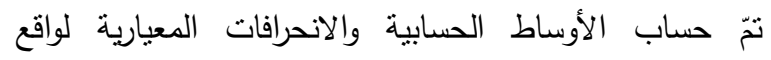
التخطيط لإدارة المخاطر في المدارس الخاصة التابعة لمديريات التربية والتعليم بمحافظة الكرك من وجهة نظر المعلمين ومجالاته تبعاً لمتغير الخبرة، وقد نبين أنه لا توجد فروق ذات دلالة إحصائية في الأوساط

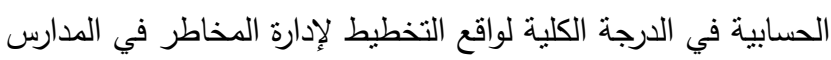

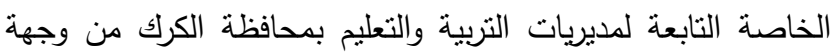
نظر المعلمين وكذلك في المجالات (الوعي بطبيعة المخاطر في

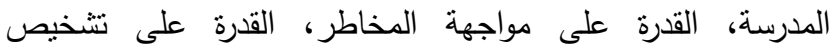

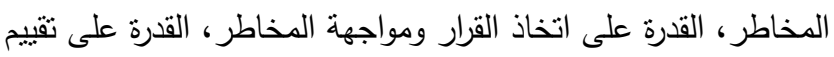

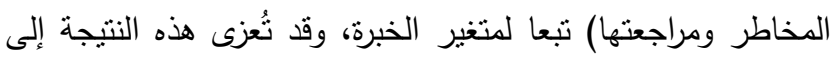

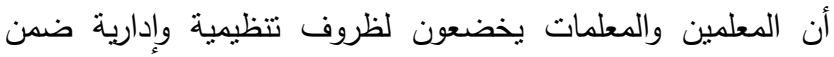

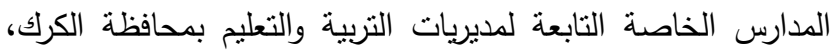
وتقع على عاتقهم نفس المسؤوليات والواجبات بغض النظر عن تفاوت

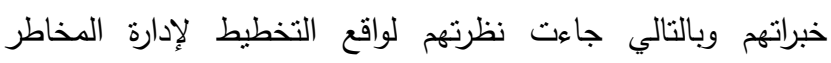

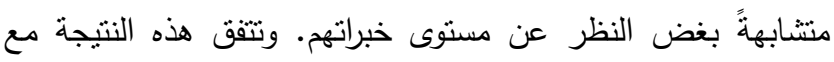
دراسة (6).

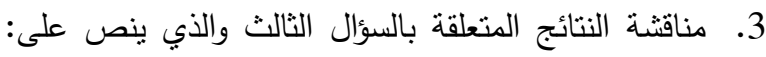

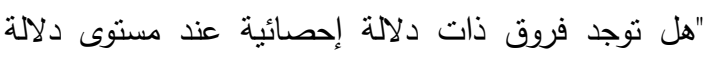

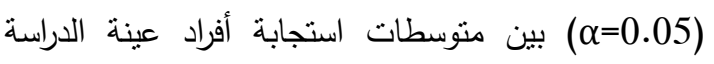

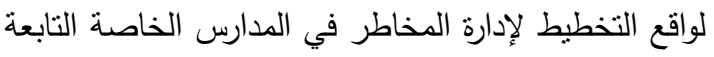

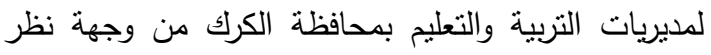

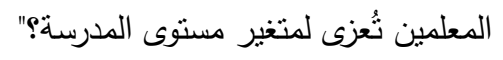

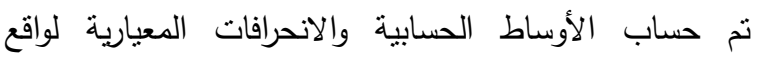
التخطيط لإدارة المخاطر في المدارس الخاصة التابعة لمديريات التربية

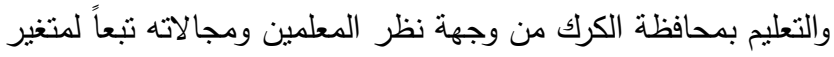

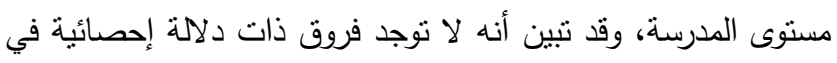

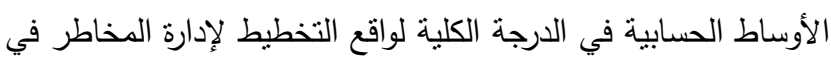

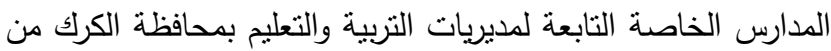
وجهة نظر المعلمين وكذللك في المجالات (الوعي بطيبعة المخاطر

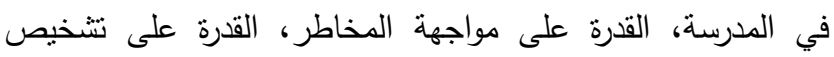
المخاطر ، القدرة على اتخاذ القرار ومواجهة المخاطر ، القدرة على تقييم

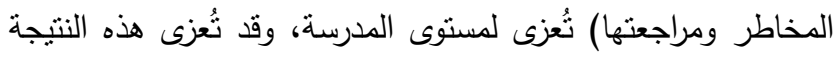

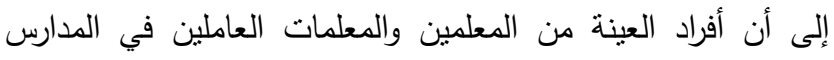

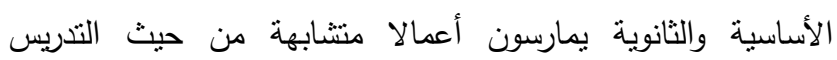

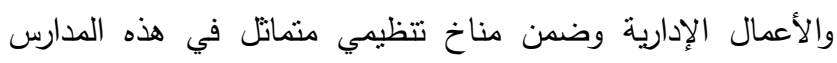

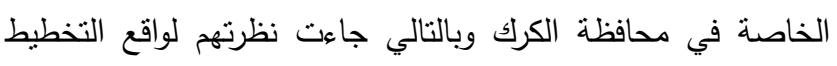


by Centering Strategic Planning: Field Research at the Ministry of Electricity", Journal of Economic and Administrative Sciences, 22 (92), 159-196.

19. Nassef, Mervat (2012). "Risk Management an Introduction to Achieving Safety in Vocation Secondary Schools in Egypt", Education Journal, 15 (23), 33_145.

20. Al-Najjar, Ghassan Muhammad (2017). "The Impact of Risk Management among Entrepreneurs in Achieving the Competitive Advantage of their Projects, Case Study: Incubator Projects for Business and Technology at the Islamic University". Unpublished Master Thesis, Islamic University - Gaza.

21. Ministry of Education, Crisis and Risk Management Strategy (2012).

22. Ministry of Education, Crisis and Risk Management Strategy (2018).

23. Adam, C. \& Kristonis, W. (2012). "An analysis of secondary schools risk management prep redness", in the National Journal for Publishing and Mentoring Doctoral Students Research, 1 (1), 20-35.

24. Arunrangsiwed, P. (2014). "Science School was Burned: a Case Study of Crisis Management in Thailand", in the International Journal of Social, Behavioral Educational, Economic, and Management Engineering, 8 (7), 2231-2239.

25. Booker, L. (2014). "Crisis Management: Changing Time for Colleges", in the Journal of College Admission, 4 (2), 17-23.

26. Elliots, D. (2010). "The Failure of Organization Learning from Risk", in the Journal of Contingences and Crisis Management, 17(3), 100-123.

27. Helsloot, W. (2006). Risk Management in Higher Education

28. Jureepan, P. \& Sirisuthi, C. \& Ieamvijam, S. (2014). "Development of Risk Management System in Private school General Education", in the Asian Social Science, 10(1), 276-282.

29. Megginson, W. \& Bortolotti, B. D'souza, J. Fantini, M, L (2000). "Privatization and the Sources of Performance Improvement in the Global Telecommunications Industry", in the Telecommunication Policy, 26 (5-6), 243268.

30. Mwangi, N. \& Kwasira, J. (2016). "Influence of Risk Management Practices on Successful Implementation of Kiambu, Kenya", in the the International Journal of Business \& Managements, 4(3), 291-311.

31. Pattanajureepan، P. \& Sirisuthi، C. \& Ieamvijam, S. (2014). "Development of Risk
8. Al-Zahrani, Siham Hatim (2012),

"Professional Standards for Leading Change among the Heads of Public Public Education Schools in Makkah AlMukarramah", Unpublished Master Thesis, Umm Al-Qura University, Saudi Arabia.

9. Al-Shraideh, Hayam, Al-Araji, Asem (2013). Dealing with Job Crises in the Framework of Decision-Making in Secondary Schools in Jordan. Amman: University of Jordan Library.

10. Saleh, Faten (2010). Crisis Management for Principals of Secondary Education Schools in Baghdad Governorate. Unpublished Master Thesis, University of Baghdad.

11. Al-Abbasi, Fadi (2015). "A Proposed Scenario for Managing School Risks in Egypt in the Light of Some Foreign and Arab Experiences: A Comparative Study", Educational and Social Studies, 21 (4), 984_911.

12. Obaid, Iman Ahmed (2015). "A Proposed Strategy for Developing the Follow-up System in the Ministry of Higher Education in the Governorates of Gaza According to Quality Administrative Performance Criteria". Unpublished Master Thesis, Islamic University - Gaza.

13. Ali, Karim (2016). Crisis management for chairmen of academic departments. Journal of the College of Basic Education, 22 (94), 705 - 724 .

14. Al-Anzi, Saad; Al-Dulaimi, ARK (2015). "Impact of Risk Management and Its Benefits on Organizations: Theoretical and Analytical Approach". Anbar University Journal for Economic and Administrative Sciences, 7 (13), 969_958.

15. Al-Anzi, Abdulaziz (2016). "The Role of School Administrations in the State of Kuwait in Facing Dangers of Social Media". Unpublished Master Thesis, University of Al-Bayt.

16. Al-Mikhlafi, Turki (2019). "The Degree of Application of Risk Management to Government School Leaders in the Qassim Region", Journal of Reading and Knowledge, 1 (207), 15_51.

17. Almushaqabat, Mataeb (2018). "The Degree to which School Principals in Zarqa Governorate Possess the Skill of Managing School Crises from their Point of View", Journal of Educational and Psychological Sciences, 2 (29). 68_83.

18. Muzaffar, Duha Basil (2016). "The Impact of Leadership Styles on Crisis Management 
Schools in Thailand", in the International Education Study, 10(3).

34. Wheelen, Thomas L. and Hunger, J. (2012). Strategic Management and Business Policy towards Global Sustainability, Thirteen Edition, Pearson Education, Inc., publishing as Prentice Hall, 100-147.

35. Wilkins, I. (2010). "An analysis of program risks management leading towards the development of a model for secondary school", in the Dissertation Abstract International, 8(58), 32-48.
Management System in Private School General Education", in the Asian Social Science, 10(1), 276-282.

32. Ridha, M., \& Alnaji, L. (2015). "Analysis and Measurement of Risks in Business: A Case Study on the Jordan Valley Authority". European Journal of Business and Management, 7(9), 9-19.

33. Wandee, M \& Sirisuthi, C \& Leamvijarm, S (2017). "The Study Elements and Indicators of Risk Management System for Secondary 